AVATARME: DIGITAL AVATARS IN A THEME PARK QUEUE CREATING A BETTER EXPERIENCE AND AN EMOTIONAL CONNECTION

by

\title{
Winona So
}

B.A. Honours English, University of Waterloo, 2015

Waterloo, Ontario, Canada, 2015

\author{
A Major Research Paper \\ presented to Ryerson University \\ in partial fulfillment of the \\ requirements for the degree of \\ Masters of Digital Media \\ in the program of \\ Digital Media
}

Toronto, Ontario, Canada, 2017

(C) Winona So, 2017 


\section{AUTHOR'S DECLARATION FOR ELECTRONIC SUBMISSION OF A MRP}

I hereby declare that I am the sole author of this MRP. This is a true copy of the MRP, including any required final revisions.

I authorize Ryerson University to lend this MRP to other institutions or individuals for the purpose of scholarly research.

I further authorize Ryerson University to reproduce this MRP by photocopying or by other means, in total or in part, at the request of other institutions or individuals for the purpose of scholarly research.

I understand that my MRP may be made electronically available to the public.

Winona So 


\title{
AVATARME: DIGITAL AVATARS IN A THEME PARK QUEUE \\ CREATING A BETTER EXPERIENCE AND AN EMOTIONAL CONNECTION \\ Master of Digital Media, 2017 \\ Winona So \\ Master of Digital Media, Ryerson University
}

\begin{abstract}
Research has shown that through customization, a user can create a longer and more meaningful connection with their avatar. This research harnesses this emotional bond in order to create a more engaging experience in the queue at theme parks. Two methods were used to collect information. The first was an online survey about queuing, Bitmoji, and theme park behavior. The second was an on-site observational study to gain a more detailed look into guest behavior in a theme park queue. This research concludes with mockups and documentation for implementing a park-wide avatar system for alleviating queue boredom for the end user. Queues are not only for holding guests in a fair line, but for on-boarding, for the immersive story and background, and for entertainment. By personalizing and customizing the experience for the guest, a more enriching and emotional connection can be made to the attraction, and the park itself.
\end{abstract}




\section{ACKNOWLEDGMENTS}

Before exploring the magical world of theme parks and the stories they create for their guests, some acknowledgments are in order.

First and foremost, my parents, who have supported me the entire way and always believed in providing me with the opportunities to explore my dreams and aspirations thank you.

To all my friends and MDM colleagues who supported me along the way, thank you for keeping my spirits up. In particular, Madeline So, for always being there for me - thank you; Steve Cober, for bouncing ideas off of and traveling together to Florida - twice! thank you; and James Zhang, for supporting me, editing my paper, and all the late nights listening to me - thank you.

To my professors, advisors, Michael Carter, Alex Ferworn, and Sonya Taccone: for aiding and advising me, and pointing my research in the right direction - thank you.

Last, but most definitely not the least, my supervisor, Dr. Kathryn Woodcock, whose help was absolutely invaluable during the entire process. When she introduced me to the world of theme parks I would have never imagined that I would return to Florida multiple times in a single year or eventually write my research paper about this amazingly deep world - so for that, and so much more, thank you. 


\section{TABLE OF CONTENTS}

AUTHOR'S DECLARATION FOR ELECTRONIC SUBMISSION OF A MRP .................................... ii

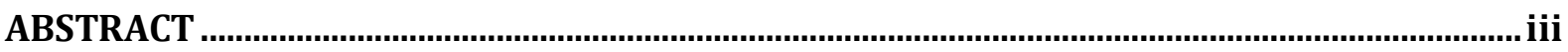

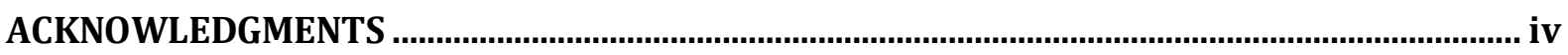

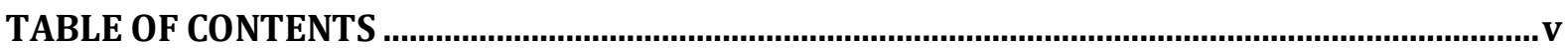

LIST OF TABLES

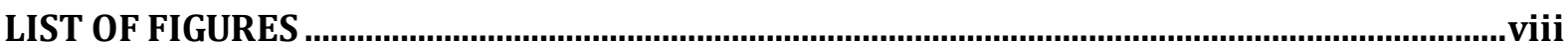

1. Introduction

2. Background

2.1 Theme Parks.............................................................................................................................................

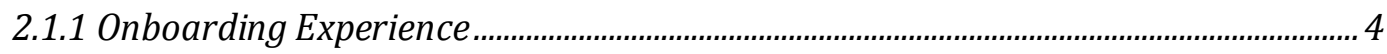

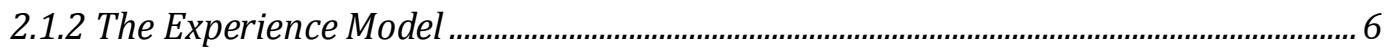

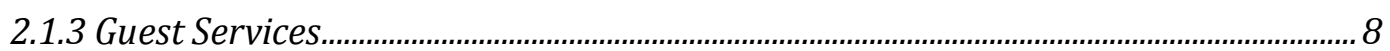

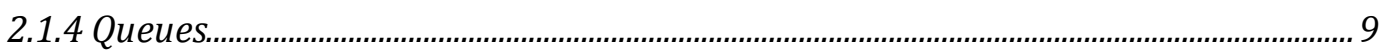

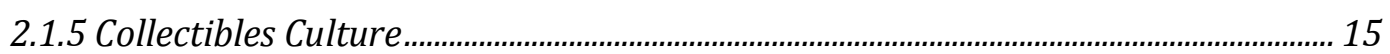

2.2 Digital Applications.................................................................................................................. 17

2.2.1 Virtual Magic Kingdom Game ........................................................................................ 17

2.2.2 My Disney Experience Program ................................................................................... 17

2.2.3 Snapchat and Bitmoji................................................................................................. 19

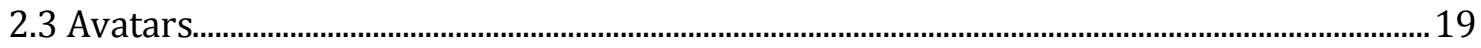

2.3.1 Avatar Creation Process................................................................................................... 20

2.3.2 Self-Identification with Your Avatar ............................................................................. 24

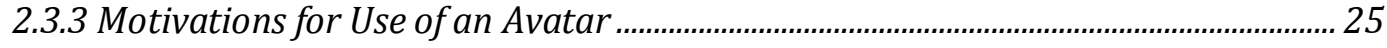

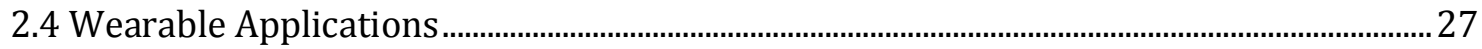

2.4.1 Disney MagicBand...........................................................................................................2 27

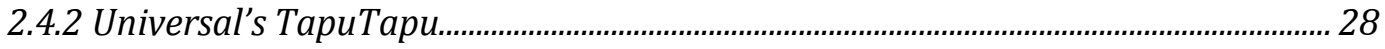

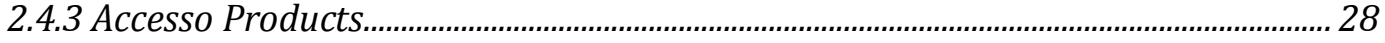

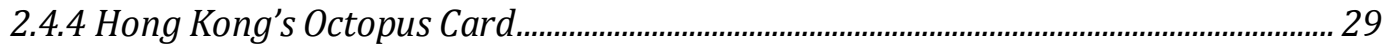

2.5 Opportunities for Development ...............................................................................................

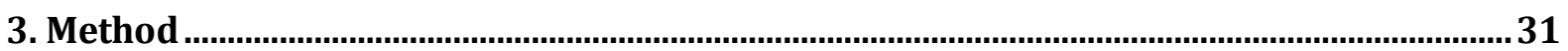

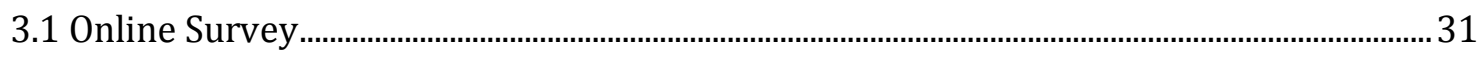

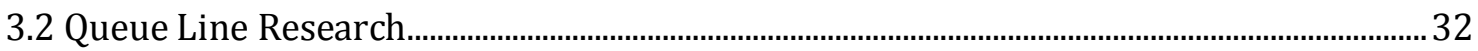




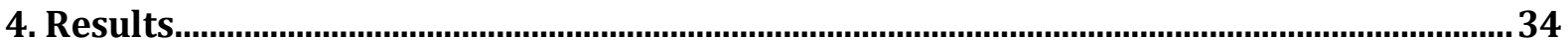

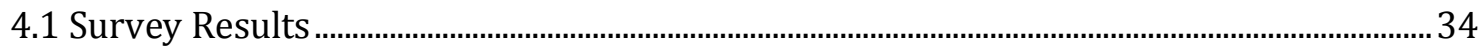

4.1.1 Survey Demographic Results....................................................................................... 34

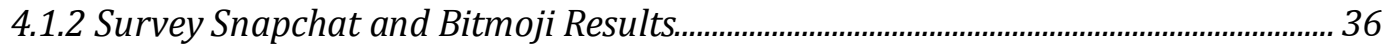

4.1.3 Survey Theme Park Results............................................................................................... 40

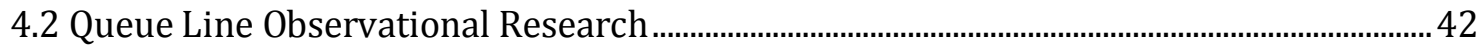

4.2.1 My Disney Experience and Disney MagicBand............................................................ 43

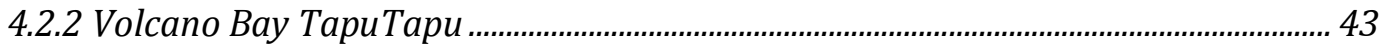

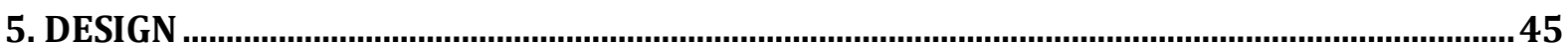

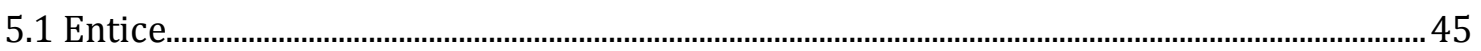

5.1.1 On-Boarding and Creation Process............................................................................... 46

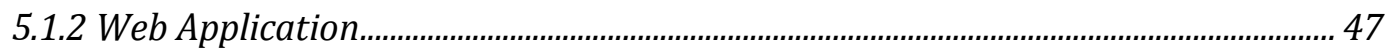

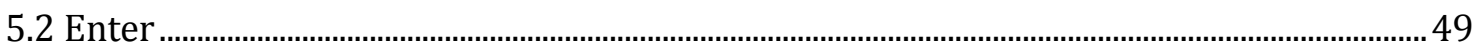

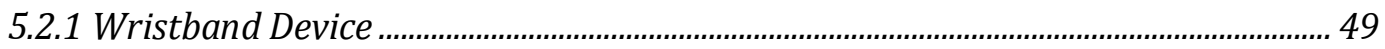

5.2.2 Contact Point

5.3 Engage

5.3.1 Queue Line Entertainment..................................................................................... 51

5.3.2 Screen Installation ......................................................................................................... 51

5.3.3 Payment Services ........................................................................................................... 52

5.3.4 Merchandising Opportunity .................................................................................... 53

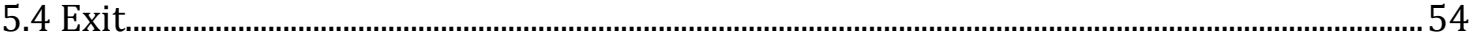

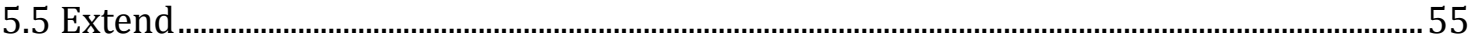

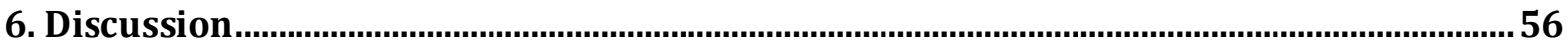

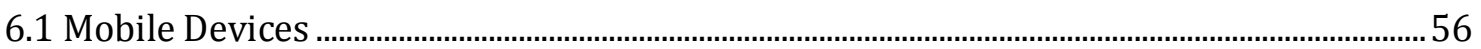

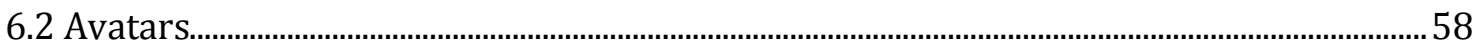

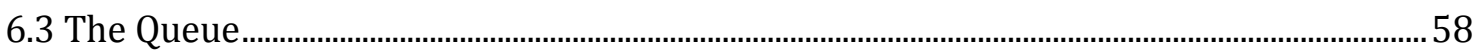

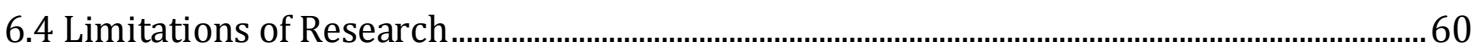

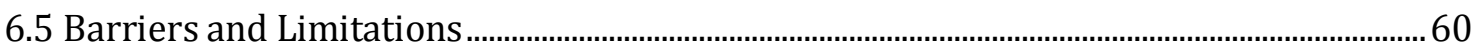

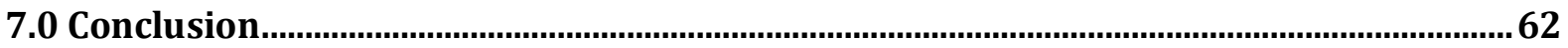

Appendix A

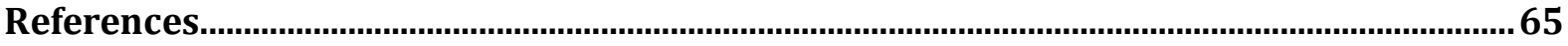




\section{LIST OF TABLES}

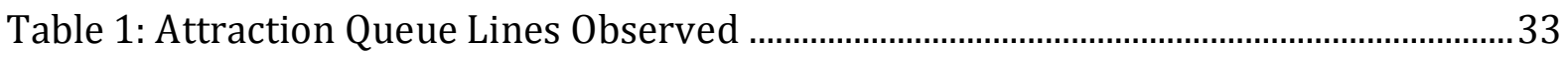

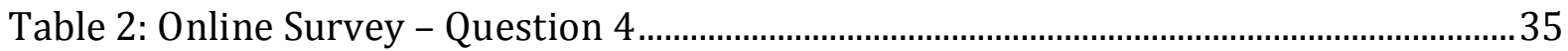

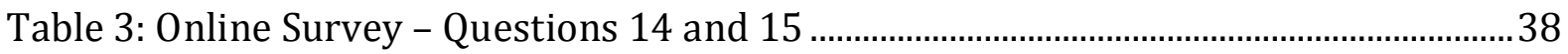

Table 4: Online Survey - Responses to Question 12 ..................................................................... 39 


\section{LIST OF FIGURES}

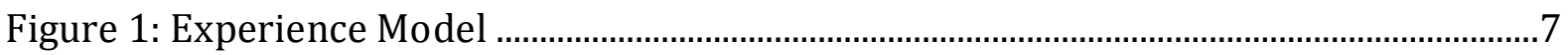

Figures 2: The interactive queue at Many Adventures of Winnie the Pooh.........................14

Figures 3: The interactive queue at The Seven Dwarfs Mine Train.......................................15

Figure 4: Pick a Disney Character for My Disney Experience ...................................................18

Figures 5: My Disney Experience Mobile Application ...................................................................18

Figures 6: Creating your Bitmoji Character ..................................................................................... 21

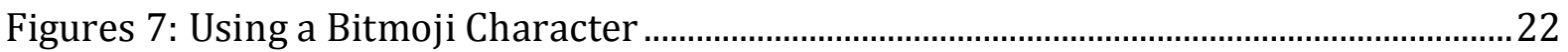

Figures 8: Creating a Disney Emojify Me Avatar...................................................................... 24

Figure 9: Exploded View of TapuTapu...................................................................................29

Figure 10: Online Survey - Gender Results ……............................................................................. 34

Figure 11: Online Survey - Age Results ........................................................................................... 34

Figure 12: Online Survey - Activities in Line .............................................................................. 34

Figure 13: Online Survey - Question 4 Averages ......................................................................... 35

Figure 14: Online Survey - Snapchat and Bitmoji Usage.............................................................. 36

Figure 15: Online Survey - Facial Features ………......................................................................

Figure 16: Online Survey - Clothing Options ............................................................................... 36

Figure 17: Online Survey - Theme Park Attendee ........................................................................ 40

Figure 18: Online Survey - Theme Park Purchases..................................................................... 40

Figure 19: Online Survey - Reason for Purchasing a Pass .......................................................... 40

Figure 20: Online Survey - Disney MagicBand Usage ................................................................... 41

Figure 21: Online Survey - Disney Annual Pass .............................................................................. 41

Figure 22: Queue Line Observational Research .......................................................................... 42

Figure 23: TapuTapu Onboarding Pamphlet.............................................................................. 44

Figure 24: Web Application - Choose a park ……............................................................................. 47

Figure 25: Web Application - Choose a costume ………............................................................. 48

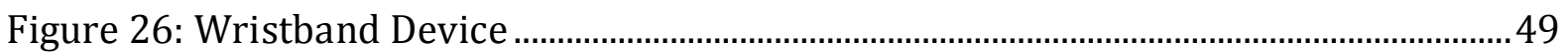

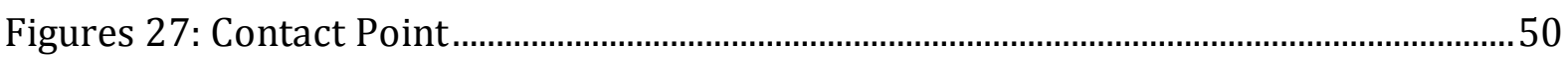

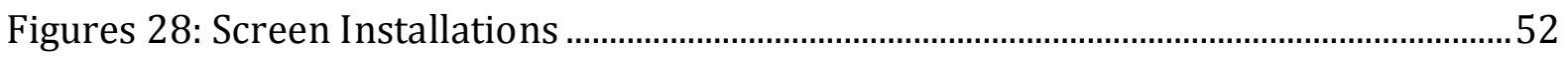

Figure 29: Avatar Action Figure at Disney Animal Kingdom ……............................................53

Figure 30: Web Application - Share your AvatarMe ................................................................. 54 


\section{INTRODUCTION}

Theme parks are environments that encapsulate retail stores, attractions, rides, and characters, all wrapped together with a made-up history to create an emotional story for guests. In order to tell this story, parks attempt to integrate parts of the story in aspects throughout the park. Universal Studio's Wizarding World of Harry Potter has been lauded as resetting the standard for theme park environment due to its attention to detail (Niles, 2014). Everything from the cast member costumes, to the way the display windows move in store fronts are plucked out of the novel and brought to life. What seems like magic that interweaves elaborate set pieces with wands, or the quiet background music that plays throughout the area though, is really just hidden speakers and retroreflective tips embedded in the wands (U.S. Patent No. 2014/0240102 A1, 2014). Technology is not only just hidden throughout the park, $76 \%$ of guests now bring their own smartphones into the park on a daily basis (Thinkwell Group, 2013). In fact, $91 \%$ of guests actually believe that theme parks need to implement systems that allow them make purchases using a wristband or cashless device (Omnico Group, n.d.). While theme parks have begun to embrace more digital applications by implementing parkspecific mobile applications for maps and queue times and more complex park-wide integrations like the Disney MagicBand, there has not been a digital approach designed for alleviating the tedious moments in the queue. Queues are an inevitable part of a guest's experience in theme parks, even as companies begin to experiment with virtual queues and FastPasses which allow guests to avoid physically standing in line and return to the ride at a later time instead.

Chapter 2 will detail the research starting with a literature review on themed entertainment with a focus on the queuing process, digital applications in themed entertainment, and avatar creation and identification. The literature review will provide the necessary background information on the industry while focusing on the end-user, the guest. By taking a look at existing digital applications in theme parks, understanding of a park's infrastructure can be considered during the design process. Chapter 3 will follow with detailing the structure and design for the survey and observational study. Chapter 4 reports the results. This is followed by a discussion and analysis of the results from the research in Chapter 5. 
The focus in the paper is about avatars and theme parks. By determining research questions, this research will be more focused and detailed. The main research question for this paper is, "how can you increase user engagement through the use of avatars in queue lines in a theme park?'. This user engagement needs to be useful and provide value to guests, and thus the secondary question is, 'through this avatar system, how can a better user experience and an emotional bond to the park be created, in order to create a more engaging and valuable experience in the queue?'. While the two main research questions are important to the actual creation of such an avatar system, the actual implementation would be useless without adoption from users. Thus, the tertiary research question is, "how can an avatar system be designed with the end-user in mind by creating motivation for its use?' These three research questions will aid in the creation and design of a user interface and a user experience documented in this paper. 


\section{BACKGROUND}

\subsection{Theme Parks}

Although the words 'theme park' and 'amusement park' are often used interchangeably, it is important to understand the difference between the two. Themed entertainment is about creating an environment through the use of audio visual, props, and set pieces in order to create a larger story that runs throughout the guest experience. An amusement park aims to simply amuse the guests, while a theme park holds a "more interrelated entertainment collection behaving in a coordinated and immersive fashion" (Nelson, 2016). For the purposes of the research, I will be focusing specifically on theme parks, and in the narratives. The themed experience is often carried throughout the entirety of the park; the dressed up cast members, food, queues, gift shops, the rides themselves, and sometimes even the washrooms as seen at Universal Studio's Wizarding World of Harry Potter. Here, one of the characters, Moaning Mrytle can be heard talking and crying in the bathroom, similar to its original source material. Throughout the theme park, a guest has the opportunity to choose which rides, shows, and experiences, known as attractions that they wish to explore (Younger, 2016). These attractions are usually themed based on the area of land they occupy - for example, in Toyko's DisneySea, the various 'lands' are: American Waterfront, Port Discovery, Lost River Delta, Mermaid Lagoon, Arabian Coast, Mediterranean Harbour, and Mysterious Island (Disney, Tokyo DisneySea, 2017). So if a guest was in Mermaid Lagoon, they would find rides related to mermaids and fantasy, while in the American Waterfront, they would likely find rides that were more related to American events and narratives. These attractions are not necessarily based around a specific intellectual property (IP) that a company owns, but companies will attempt to place their IPs in related areas. For example, the Mad Tea Party ride based on the Alice in Wonderland is located in Fantasyland at Disney Magic Kingdom. The reason for splitting the part into different areas is twofold. The first, over choice, is related to several factors: crowds, noise traffic, special configuration, size, complexity, variety of exhibits, and manifold subject manner (King, 1991). By limiting the immediate area to only one theme, parks are able to reduce this overload of information for guests and likely more importantly, for immersion and the theme aspect. 
On average, an adult pays $\$ 84$ USD to enter a theme park, hoping to see something new, go on new rides and attractions, or enjoy themselves in a way that they could not otherwise do at home (Shallcross, 2015). None of the guest's intention is to wait in line, and despite this, a guest will inevitably spend time standing in a queue waiting for their turn. The queue in theme parks, explained in more detail later, acts as a pre-show for the attraction to come. This pre-show creates what is known as the onboarding experience in theme parks.

\subsubsection{Onboarding Experience}

Onboarding at a theme park refers to how the guest is mentally prepared for what is to come. This on-boarding area could potentially be the land that the attraction is situated in, but it can also be more contained like in the queue directly before a ride. The setting and environment does more than just simply create an impression in the guest's mind though, cues from the environment can also explain to guests where to go next, and in fact, guide the guest experience (Disney Institute, 2001). In the case of rides, the on-boarding experience happens throughout the queue, giving guests an idea of what the ride will entail, the characters, as well as putting them in the right mindset prior to the ride. The effects and themeing in the queue also develop the narrative of the ride - as guests approach the actual ride vehicles, they will have "already physically and cognitively moved through much of the story that the ride will complete" (Lukas, 2008, p. 154). While the on-boarding experience can describe any show elements a guest experiences before the attraction, a 'preshow' describes specifically to "any presentation, whether live performance, video, animatronics, or a dedicated scene shown before boarding the attraction" (Younger, 2016, p. 479).

Since many rides are often based on existing movies or IPs, the preshow often brings in elements from the movie in attempt to connect the ride to the already existing properties. Some guests may not be familiar with the original property and the preshow helps give them enough background information for them to understand the setting of the ride. For guests who are familiar with the original IPs, it becomes more of an easter egg-hunt when they recognize props and characters from the movie. The queue also communicates the background and sets up the experience for the guest - this allows the "attraction itself to focus solely on the more dramatic parts" (Younger, 2016, p. 475). A recent example of this is at Disney's newest land, Pandora: World of Avatar. James 
Cameron's Avatar movie introduces the audience to the main character, Jake Sulley, and the world of Pandora by showing Jake's Na'vi avatar floating in a large enclosed tube. This scene is the very first exposure that the audience has to the Na'vi people. Similarly, in the Flight of Passage ride in Animal Kingdom, after guests walk through lush scenery areas, they encounter a giant animatronic of a Na'vi avatar, floating in the same enclosed tube, with a photo of both the avatar and its controller on the computer screen next to it. For guests who are not familiar with the Avatar movie, this tells guests the story of how humans have a Na'vi avatar. For guests who have seen the movie, this is a great reminder of the film, where Jake learns how the avatars work in Pandora. In fact, Disney refers to the queue as "scene one" - implicitly tying the queue as part of the attraction (Ledbetter, 2016).

However, sometimes the ride may not align with the guests' expectations. When the Snow White ride first debuted in 1955, the ride told a completely different and scarier version of the Snow White story. The onboarding experience during the queue included a colourful mural depicting Snow White with her forest friends (Rahn, 2000). The ride itself however, was a dark ride that focused around the witch and the dark scary forest. The disconnect between the on-boarding experience and the actual ride was very distressing to guests who were expecting a more family-friendly experience. Since then, it has been redesigned several times to make the entire ride less scary, and to feature Snow White and the Dwarves more prominently in order to create a better experience. Theme parks use many different techniques in order to provide a staged authenticity in the queue in order to create a more comfortable and enjoyable experience in the queue (Daniels, 2016).

Daniels studied queues which used the technique of suspended reality in order to extend the attraction experience into the queue environment, keeping guests busy and entertained (2016). By finding interesting details and entertainment around them, guests would perceive the wait time to be shorter than it actually was. Daniels created a system in which she would rank popular attractions based on their queue design on 12 categories: architecture, surrounding materials, lighting, audible sounds, atmosphere, props, effective form and shape of line, plant materials, interactive elements, technology, key visual elements, and views (2016). Each element would be scored from one to five, giving each attraction's queue a suspended-reality (SR) score. By comparing guest perception of the amount of time passed to the SR scores, Daniels was able to 
determine whether a ride with a higher SR score would result in guests perceiving a shorter period of time than the actual wait time. Using Friedman's statistical tests, the results only showed a modest significance (Daniels, 2016). These results show that the technique of using suspended reality does not actually reduce the perceived amount of time passing for guests - and thus future enhancements made to queues should take this into consideration, particularly when dealing with the environment and immersion in the queue.

A good onboarding experience in the queue can set a guest's expectations for a ride, however onboarding is evident throughout the entirety of a theme park. The lands surrounding the attraction also onboard the guest for that area, and parks often utilize transition points between different lands so that guests are not confused. In Universal Studios Florida, these transition areas are the bridges that link each land to the next. By keeping each land separate and themed appropriately, parks can avoid overloading guests with too much information at one time, creating a better overall guest experience (King, 1991). The guest experience in theme parks is, of course, a high priority to the parks, and any changes or developments are always made with the guests in mind.

\subsubsection{The Experience Model}

The experience model is a model used to explain the different aspects of the user experience and how to create an engaging experience for the end user. The experience model consists of 5 E's: Entice, Enter, Engage, Exit, and Extend (Figure 1). Each of these stages is a vital part of the experience. This experience model can be used for physical experiences, like rides and attractions, or digital experiences like playing a video game. The entice stage is the very initial impression that the user gets during the experience. The purpose is to entice and encourage the user to use the system. It often contains part of the initial story to introduce the user to the backstory if there is one. The enter stage is where the user begins to actually use or experience the system. The engage stage is for encouraging users to actually engage with and use the system. The exit stage is how the experience appears to end for the user. This stage is about thinking about how they left the experience, whether they have a bad taste leaving the experience, and the user's final impression. The extend stage is about bringing the experience beyond the end. This is in order to encourage repeat customers and have them share their experience. 


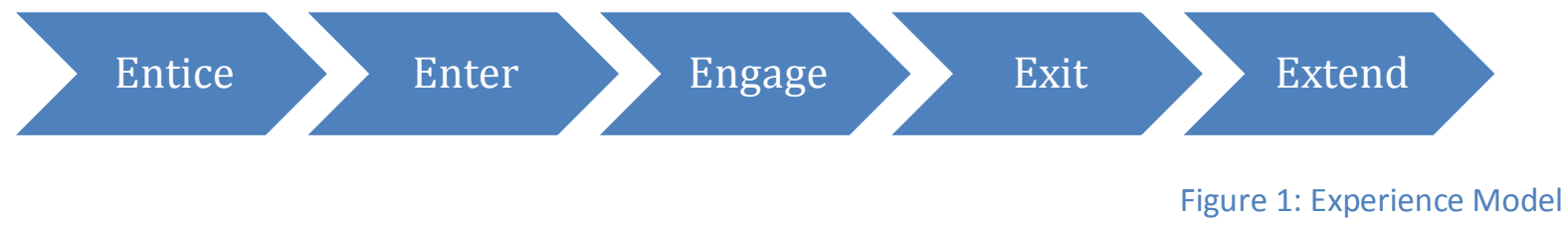

The experience model will be explored in more detail in Chapter 5 as it applies directly to the theme park industry.

\subsubsection{User Experience}

In digital applications, the user experience refers to how an application's interface feels to the user - is it intuitive to use? Do the buttons and links lead the user to what they expected? When these experiences are designed with the user in mind, this is known as human-centered design. This philosophy proposes that the end users be at the center of technical system designs (Johnson, 1998). In themed entertainment, the user experience stretches beyond just a digital screen. Theme parks constantly have the guest experience at the forefront of their design - by keeping guests happy and entertained, they will be more willing to spend more money and time at the park. Disney has created a set of 'Four Keys' that are used to create a great guest experience: safety, courtesy, show, and capacity (Disney's Four Keys To A Great Guest Experience, n.d.). These keys are used to guide employees and contractors to create better attractions and experiences for the guests. This can be very simple from ensuring that dangerous areas are roped off accordingly and appropriate warning signs are posted, or more elaborate like how signs are placed throughout the parks for guests to understand where they are in the park, and how to move to their areas of interest.

Universal design is the concept of designing for all people - it is not just simply 'good' design. It attempts to ensure that the user interface and the experience is accessible for people of all demographics. At theme parks, they attempt to address this in a variety of ways - wheelchair-specific ride vehicles, hearing-aid devices for different shows and larger ride vehicles, just to name a few. Universal design attempts to address the "four A's" - accessibility, adaptability, aesthetics, and affordability (Null, 2013). Accessibility is ensuring that there are no physical barriers that hinder people unnecessarily. For example, there are many strollers at theme parks because of their family nature - is it easy for guests to move around the park while pushing a stroller are there curbs or ledges that make it difficult? There are additional benefits of ensuring 
universal design - it is more economical. Since it does not focus on creating environments for an individual disability, it actually standardizes things that can be beneficial for everyone.

\subsubsection{User Interface}

The user interface is the part of the design that a user can physically see or touch, not the experience. On a phone, it is the way the icons and buttons are laid out to use, or on a laptop, it is what is on the screen. In a theme park, the user interface refers to what the user can actually interact with - when they enter the park, what does the screen look like when they wish to purchase tickets. When a guest picks up a map, how does that map illustrate the different lands and attractions, and how does it direct a guest to each area. In queues, there is not an interface that guests necessarily use, but there are signs which show warnings and notices to guests. Other interfaces that a guest will encounter in a theme park are screens where they order food, merchandising payment services, and games. Guests also interact with their own phone's interface throughout the park when they take photos, post on social media, or browse the internet. Poor usability in the interface detracts from everyone's user experience - and by improving the interface and usability for all users, the experience is actually improved for all users.

\subsubsection{Guest Services}

Guest services is a blanket term used when workers of the theme park aid or guide guests. In order to maintain a workplace that is customer oriented and focused on delivering quality at all times, parks need to train employees to ensure a great guest experience. This training process can be quite rigorous for new cast members. For example, at an anonymous Florida theme park, new employees attend one-day training seminar, followed by extensive on-site training which could range from a few days to several weeks, depending on their area of service (Hickman and Mayer, 2003). The teams that work at theme parks often result in a family-like atmosphere (Hickman and Mayer, 2003). Sometimes, guest services can also grant compensation when problems arise during a guest visit like an attraction breaking down. Their goal is to create the best experience for guests and to resolve any issues or problems. Guest services can also provide attraction recommendations, route recommendations, or general helpful knowledge. Although theme parks attempt to provide a great guest experience through 
their guest services, according to studies conducted by International Air Transport Association (IATA), passengers actually prefer to maintain more control over their journey, with a large proportion preferring to use self-service and mobile applications (Duguay, 2014). Parks attempt to aid guests throughout their experience, but preserving control, or at least the illusion of control, for guests is important.

\subsubsection{Queues}

It is expected in many cultures that service, or access to a service is provided fairly - usually in the order of arrival. The queue is a physical representation of the order of arrival. Physical waiting lines send a clear message about mass cooperation they are designed to trigger the other guests' instinct for reciprocity (Fagundes, 2006). Since all the guests are following the queue's rules, it is more likely that future guests will also follow the queuing rules. In fact, some parks actually have a system for guests to call and report line cutting - and the employees will follow through to find said guests who were skipping the line (Joel, 2011). For some services, guests instead take tickets that indicate their order of arrival like at a deli counter. Although queues are part of a normal daily experience, the queue serves a slightly different purpose at a theme park. They are used partially as a way to mark who has arrived to the attraction first, but as well as a holding area for guests in the park. Park capacity takes into consideration the number guests who are in queues, not just the ones physically moving throughout the park.

Queuing theory consists of eight main components: its customers, arrival rate, servers, service rate, queue discipline, queue length, channels, and phases (Cope, R., Cope, R. F., and Davis, 2010). The customers in a theme park are the guests - the people want service from the operation. At a theme park, this is usually the attraction. The arrival rate is the frequency at which the customers, or in this case, the guests are arriving at the attraction. At park opening times, you will often see large groups of guests rushing towards what they believe are the queues which will have the longest wait later in the day in order to avoid the rush. The server is the person that performs the operation that the customers are waiting in the queue for - in a theme park, this is often the ride itself, but can also be the different rooms and areas that the guest passes through. The Simpsons Ride in Universal Studios, Florida has several holding rooms, all of which contain different cast members, videos, and entertainment. The service rate is 
the rate at which customers can be served. In a theme park, this is also known as the throughput rate (Younger, 2016). This is the number of guests that can fit on a ride vehicle and go through the ride in a given amount of time. The queue discipline is the order in which guests are served. Generally, it is first come, first serve, although at a theme park this can change when near the front of the queue, cast members will ask if there are a certain number of guests (usually 2 or 3 ) that can come up to the front to ride immediately. The cast members are trying to improve the service rate the throughput rate) by ensuring that the vehicles are as filled as they can be. The queue length is the number of customers that can fit inside the queue at a given time. At theme parks, this is usually a finite number as the queue ends at the entrance of the attraction - very rarely do you see guests lining up outside of the ride. The channel is the number of parallel servers that a customer can receive service. Sometimes at theme parks, guests can go through one queue, and in the last queuing portion be split into smaller groups, all of which can ride the attraction at the same time. The number of groups that the attraction can contain is the channel. Finally, the phases are the number of servers that the customer needs to go through in order to receive their service.

Although the queuing theory is not anything new, there have always been attempts to strategize around the queue. In the 1960s when there was a boom in the tourism market, designers thought to strategize around the efficiency of queues in order to encourage return visitors. Some of the initial attempts included adding wait time signs, and protective covering from the weather for the guests. They determined that "an ideal queue set the scene for the story and transitioned guests from the land outside to the attraction's theme", what is known more commonly as the onboarding or the preshow (Nelson, 2016). Some of the attractions adopted more waiting room style "queues" which became areas of entertainment instead. In particular, The Jungle Cruise attraction in Adventureland had a script that was edited and changed to have a more lighthearted tone - and the queue itself also was edited and changed, eventually having the queue lined with props from the ride's script. The flow of people and traffic was very important to the Imagineers, as well as Walt himself - they would spend hours playing a 'tourist' role in order to learn what the guests could be doing in the queues, and as a result, better understand how to improve the experience (Nelson, 2016).

Queues are an unavoidable point of theme parks and are the "single most frequently critiqued problem in theme parks" (Disney Institute, 2001, p. 145). Each 
attraction has their own queue which guests can choose to enter. The current wait time from the beginning of the queue to the ride vehicle is posted throughout digital signs at the park, as well as at the entrance of each ride. Guests also have the option of downloading the park's mobile application or other third-party applications in order to view the wait times prior to entering the queue. On average, a guest can spend anywhere from 45-60 minutes in a single queue for one attraction, and 90 minutes for more popular attractions (Blesgraaf, 2014). The longer a guest waits in a line, the more dissatisfaction they feel and so theme parks attempt to reduce the wait as much as they can (Jones \& Peppiatt, 1996). Ultimately, when the wait cannot be further reduced and are a necessary part of the experience, they must be, "mindful of the needs and desires of the guests" by encouraging activities which may keep them busy and happy (Younger, 2016, p. 471). This can be accomplished using a variety of techniques, discussed later on. According to research by Katz and colleagues, the reason that guests are not willing to wait for long periods in queues is because of the increase in work hours each week, and so "as consumers experience a great squeeze on their time, waits seem [...] more wasteful than ever" (Katz, Larson, B., \& Larson, R., 1991, p. 44). In addition, Katz et al. argue that the actual time does not need to be reduced - instead, improving the guests' perception of the waiting experience can be just as effective (1991).

Parks have different methods for managing the wait in lines from things like single-rider lines to FastPasses. Single-rider lines allow groups of people or single guest attendees to ride the attraction alone instead of as a group. This allows the park to fill ride vehicles much more efficiently by filling the empty seats, and therefore, improve the throughput rate. One of the drawbacks of entering the single-rider line is that the queue experience often takes a completely different path, missing on some of the immersive set pieces throughout the queue. On the other hand, Disney has created a virtual queue for their attractions known as FastPass. When a guest arrives at an attraction that they wish to ride, they have the choice to either wait in the physical line or to take a FastPass ticket at which point they can return to the attraction at a later specified time. This technique is in line with IATA's studies where guests prefer to maintain control over their own journey. FastPass has allowed Disney to significantly increase the level of satisfaction of its customers while maximizing the utilization of its attractions (Duguay, 2014). In fact, in the first five years of operation, the FastPass reduced wait times by $40 \%$ (Nelson, 2016). Queues have changed dramatically as 
designers began to understand what made a queue good, reducing stress and frustration in guests.

\subsubsection{Ideal Queue}

Although new queuing techniques are being implemented and tested at various theme parks, queues will still exist in the theme park industry for the foreseeable future. Until techniques such as the fast pass, or virtual queues can be implemented in the themed entertainment industry on a larger scale, parks must improve the existing infrastructure. Maister wrote that an ideal queue has eight tenets (2005). They are:

1. Occupied time feels shorter than unoccupied time

2. People want to get started

3. Anxiety makes waits feel longer

4. Uncertain waits are longer than known, finite waits

5. Unexplained waits seem longer than explained waits

6. Unfair waits are longer than equitable waits

7. The more valuable the service, the longer the customer will wait

8. Solo waits feel longer than group waits

(Maister, 2005)

The aforementioned tenets are important in the queue in order to create the best experience for the guests. Many of them are already implemented today to alleviate guest concerns. At almost all large theme parks, guests have an idea of how long the wait is until they reach the ride vehicle due to digital signs posted at the entrance of any attraction. In addition, by using a hidden switch-back queue, guests are waiting in groups, encouraging tenent number eight. A hidden switch-back queue occurs when guests are routed back and forth within a compact space. This allows guests to interact with each other and encourage sociality. When the queues are hidden, guests may be encouraged to line up because the line appears to be shorter than it actually is. Back when Walt Disney was working in the park, he went to ride the Calico Mine Ride, and when he walked around the back, he said, "My God, that's a sneaky thing! Here there's two hundred people in line back here and I didn't know there was anybody!" (Merritt \& Lynxwiler, 2010, p. 102).

In addition to these eight tenets, Younger actually proposes a ninth tenent for an ideal queue, "Constant gradual progress feels shorter than rare bursts of large progress" 
(2016, p. 472). This is because constant movement feels like progress, even if it's very limited progress. In addition, the novelty of a new space wears out quickly when guests are required to stand in one spot for a while.

These tenets are also supported by other research, stating that “...stimulus presented to an individual draws attentional resources away from the internal cognitive process of keeping track of time" (Ledbetter, 2016, p. 13). The role of the queue is to also distract the guests from realizing how much time is passing, or having them feel that they are wasting time standing in the queue instead of looking at attractions or actually riding attractions. It has been determined that "the longer the wait, the less the satisfaction (Jones \& Peppiat, 1996). Ledbetter also conducted a study in order to determine whether the load of cognitive processes affects a user's perceived notion of time. He found that in fact, the complexity of the task did not have an effect on the perception of time passage in guests, however, the immersion of an interactive queue does play an important role in altering a guest's perception of waiting time by $9.18 \mathrm{~s}$ (Ledbetter, 2016). This means that while the queue does not have to be complex, it does still need to be immersive for it to be successful.

In addition to the aforementioned tenets, many parks utilize queue stages because "people want to get started" (Younger, 2016). This breaks down the queue into several scenes and rooms, which guests consciously labels as part of the attraction experience. In actuality, these second stages are actually disguising the queue. In Despicable Me Minion Mayhem at Universal Studios, guests spend a portion of the queue standing in a room along with the other guests as the main characters, Gru and the sisters, speak to the guests about how they want to turn the guests into minions themselves. This stage consists of cameras, some special effects including scent, sound, and smoke, lights, and a camera that faces the audience. Since the style of humor and presentation is similar to the attraction, guests view this as part of the attraction and not part of the wait.

\subsubsection{Interactive Queues}

In order to distract guests, and keep them occupied in queues, some theme parks have used interactive elements in queues, in addition to visual scenery props. Disney has implemented many interactive queues throughout the different parks, in comparison to Universal Studios who tends to use more static queues where the guests 
do not actually physically touch or interact with the queues. There are a few queues that do have very limited interactivity, such as The Mummy ride at Universal Studios in Florida where guests can touch the cursed scarab and the lights will flicker, but the interactive queue is a hallmark of Disney queues. The scarab example in the Mummy Ride is an example of how interactive queues do not necessarily use digital applications in order to create interactivity, however this research will look specifically into digital applications in queues.

Some rides have entire areas for playing and interaction as part of the queue. In Disney's Magic Kingdom, the Many Adventures of Winnie the Pooh incorporates an open area where children are free to play while the parents are lining up for the actual ride. This area includes drums that are themed like giant vegetables, a rope to pull on which make gophers pop out of holes in the ground, a spinning wheel which makes balls pop up and down, and weight activated spots on the ground which activate different characters and sounds. These kind of open areas do not have a queue, but are just an open area as seen in Figures 2a. Later in the actual queue, there were also large digital screens where guests could "wipe honey" away from the different characters (Figures $2 \mathrm{~b}$. These are passive games that are quick to learn through either experimentation or observation, and had no winning or losing conditions. This open area queue is also implemented at Disney Epcot prior to the Turtle Talk with Crush show where children can look into tanks with different sea creatures or play quiz games on screens.

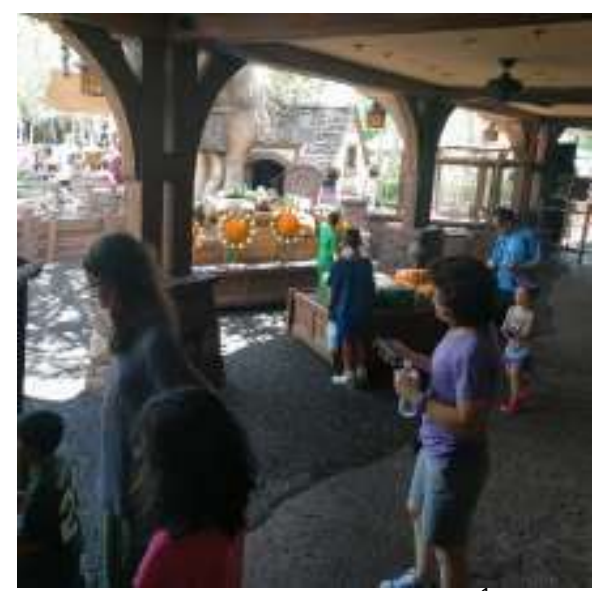

Figure 2a: Open play area ${ }^{1}$

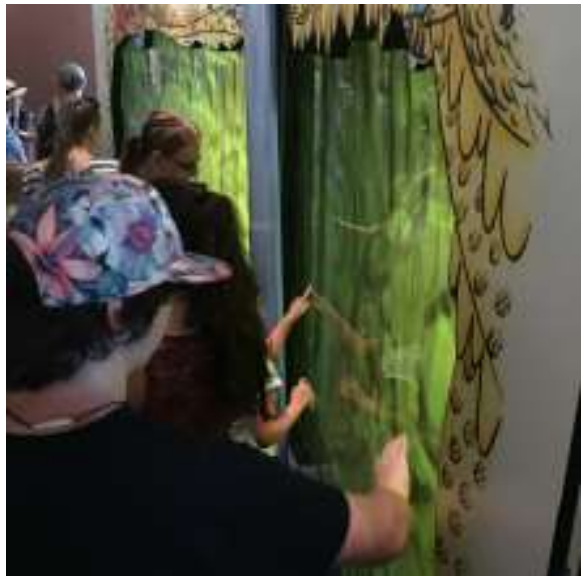

Figure $2 \mathrm{~b}$ : Interactive game screen where guests can wipe honey off characters ${ }^{2}$

Figures 2: The interactive queue at Many Adventures of Winnie the Pooh

\footnotetext{
${ }^{1}$ (So, 2017)

2 (Cober, 2017)
} 
The Seven Dwarfs Mine Train is another attraction in Magic Kingdom that incorporates an interactive queue. The first portion of the queue has no interactive or themed parts other than the music playing over the speakers and the actual building looked like a log cabin in the woods. Once inside the building, there is a portion of the queue that had an interactive tablet where guests waiting can play a game by dragging crystals into storage. This game is quick and easy to learn meaning guests could simply walk by to play a quick game, or stay around to play a little longer as seen in Figures 3 a. Later in the queue, guests also have the opportunity to block streams of water which creates different musical tones. Finally, once inside the building, guests can spin large barrels of "crystals" as seen in Figures 3c. When spun fast enough, the dwarves from Snow White appear on the ceiling and if all barrels are spun at the same time, Snow White herself appears in the center. The queue games implemented by Disney have no "winners" - instead, the game resets, making the game more approachable for children, and allowing them to move along as the queue moves along.

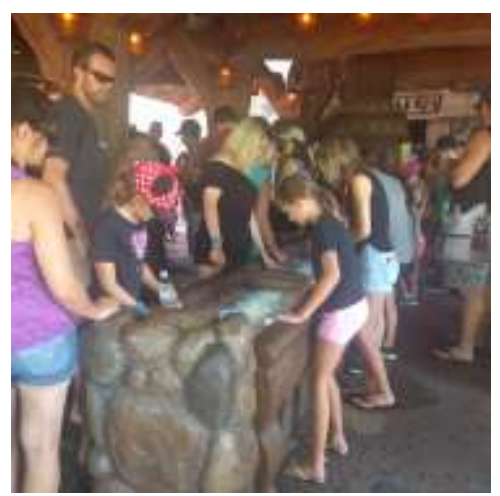

Figures 3a: Drag and drop mine game

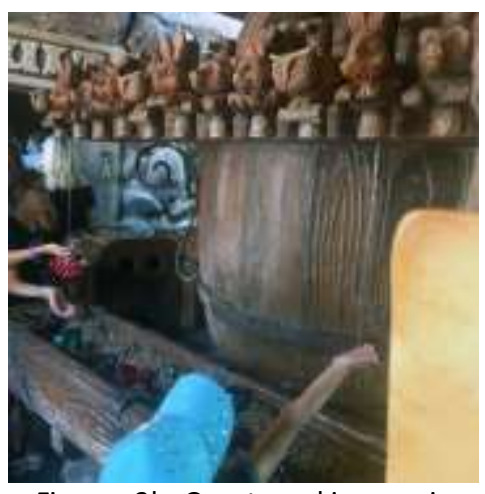

Figures 3b: Guests making music with water spouts

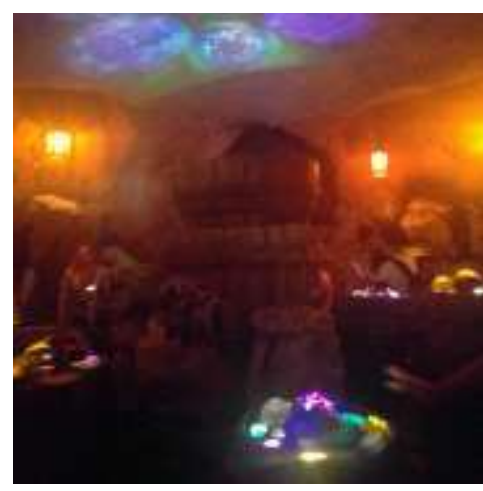

Figures 3c: Guests spinning barrel game

Figures 3: The interactive queue at The Seven Dwarfs Mine Train

\subsubsection{Collectibles Culture}

The idea of "collecting" is a huge part of the fan culture at theme parks. One of the biggest collectible items is the Mickey ears featured at Disney resorts and parks. They began in the 1950s when the Mickey Mouse Club wore them on television. Since then, hundreds of different official ears have been manufactured by Disney, as well as thousands of fan-created ones. Also popular at Disney parks is the practice of buying and trading collectible pins. This hobby is officially supported and promoted by Disney through the merchandise as well as through the cast members. Many cast members

\footnotetext{
${ }^{3}$ (So, 2017)
} 
wear pins on lanyards or on a bag solely for the purpose of trading pins with guests. There are over 100,000 different Disney pins available, and as new pins are released, they are announced on the Disney Parks Merchandise blog. There are even pin trading etiquette guides for guests and cast members in order to ensure fair and proper pin trading. Another popular collectible, particularly in the Japanese Disney parks is Duffy the Disney bear. Duffy is a stuffed plush bear (along with his sidekick, ShellieMay), who have hundreds of different dress-up costumes and accessories that can be purchased. Although originally sold in Orlando, it was not until Oriental Land Co. purchased the rights to sell them, and aggressively marketed it in Toyko DisneySea park that Duffy became a common sight in the Japanese parks (Inagaki, 2010).

A more traditional collectible is the pressed penny - also known as the elongated coin. These are available throughout the world, usually in areas where there are tourists - museums and landmarks for example, not only at theme parks. A user will pay both the cost of the using the penny press (usually a dollar or so), as well as providing the penny. They can then crank a lever which presses the penny into an elongated shape, stamped with something from the location they are at, to serve as a souvenir. These are available at both Disney and Universal Studio theme parks.

Theme parks encourage this collectibles culture as it generates huge amounts of revenue - and it is not only limited to merchandise. At the completion of a Disney marathon, runners receive a medal for their specific marathon. However, if the runner completes a runDisney in both a Walt Disney World resort (in Florida, Orlando), as well as at the Disneyland Resort (in Anaheim, California), they can receive a Coast to Coast Race Challenge Medal. Guests have also been heard to "collect experiences" at the theme parks. When The Twilight Zone Tower of Terror ride in California was announced to be shut down to make space for the Guardians of the Galaxy - Mission: Breakout! ride, guests rushed to ride the Tower of Terror version of the ride before it was shut down and gone for good. 


\subsection{Digital Applications}

\subsubsection{Virtual Magic Kingdom Game}

The Virtual Magic Kingdom game was a massively multiplayer online game containing a virtual representation of a Disneyland theme park with areas and mini games. Originally, the game was created in 2005 in order to celebrate Disneyland's 50th anniversary, but due to the popularity of the game, it stayed available until it finally shut down in 2008. Players were able to create an avatar, customizing the clothing, hair, face, and skin colour. In addition, players had a guest room which they could decorate with items that they earned in-game. Players were able to hang out online in the virtual park, chat, and play games with other guests. There were many mini games that guests could play including checkers, a ship battle game based on the Pirates of the Caribbean ride, and the Haunted Mansion game where guests had to capture ghosts in the mansion. In addition to in-game quests and adventures, there were also in-park quests where guests earned special in-game prizes at Disneyland and the Walt Disney World resorts.

Since being shut down, many people have tried to bring it back through fan recreations - the most popular being My Virtual Magic Kingdom. Fans still reminisce on the old game, commenting "I played it a lot when I was younger and my family couldn't afford to go to Disney" (Reddit, 2012).

\subsubsection{My Disney Experience Program}

The Disney Experience Program is an online portal which assists a guest in the planning and during their Disney vacation. This portal is available both through an internet browser as well as through a phone application. The portal allows a guest to book a Disney resort, purchase tickets for the parks, and make reservations for food. When registering, guests have the ability to choose a Disney character to represent themselves in the application (Figure 4). The avatar does not have any actual functionality other than for visual interest and self-recognition in the application (Figures 5). It is a good visual clue for guests to find their party in the application as they can confirm the character after searching up their fellow guests. 


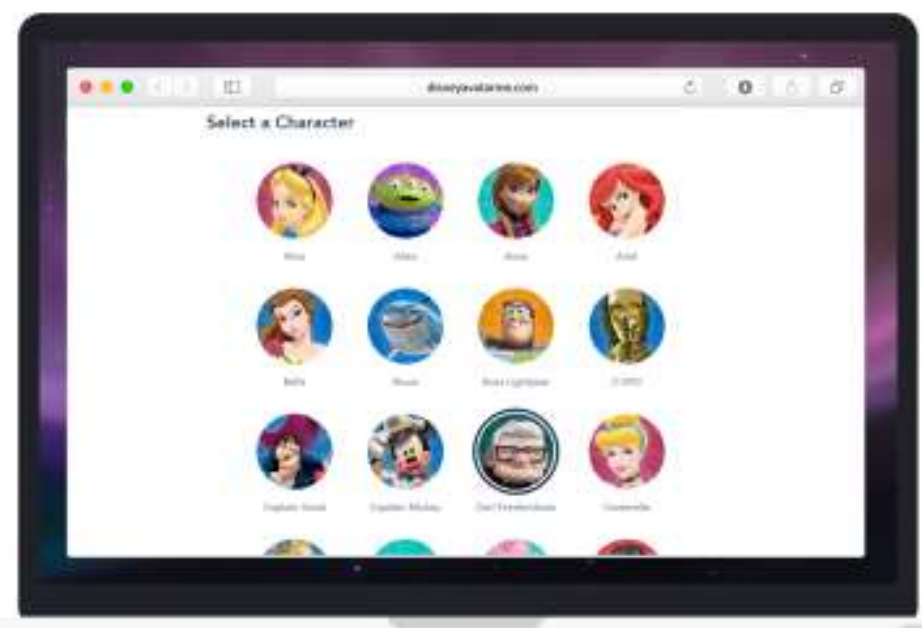

Figure 4: Pick a Disney Character for My Disney Experience ${ }^{4}$

The phone application is used primarily inside the park. Guests are able to do a variety of different actions like order food, receive notifications, check resort details, look at the schedule for special events, or even browse wait times for rides and attractions (Figures 5). The application is also personalized for each person's trip, but there is not an actual representation of the guest in the application. Additionally, the application is linked to a guest's MagicBand. After a cast member has taken a photo of the guest, they can tap the guest's MagicBand to a handheld device. Later in the day, guests can then use the application to browse or purchase photos that cast members have taken of them earlier in the day.
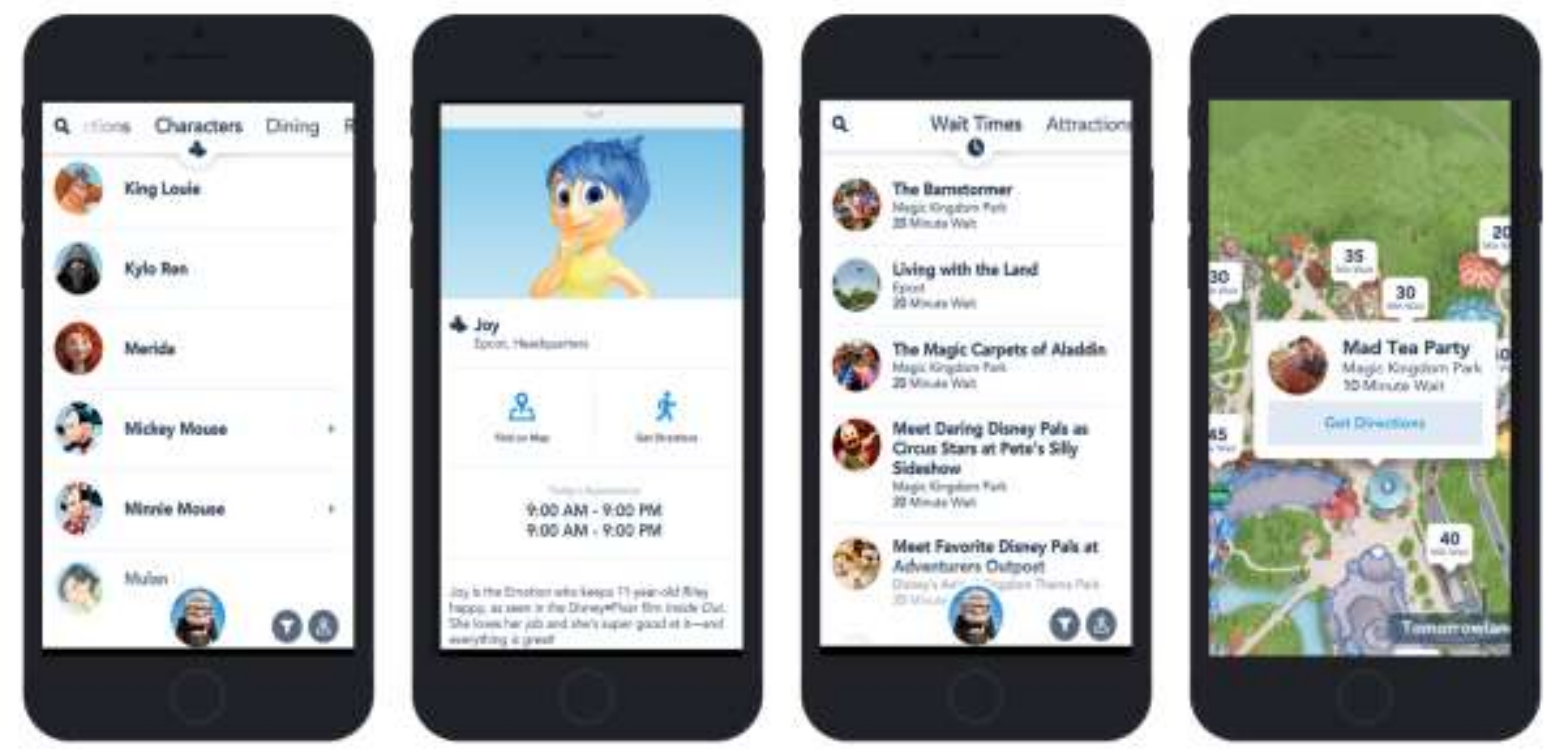

Figures 5: My Disney Experience Mobile Application ${ }^{5}$

\footnotetext{
${ }^{4}$ (Disney, Select a Character, n.d.)
} 
This program also incorporates non-digital aspects, in particular, a mailer sent to the guest's home prior to the trip with more details about the trip and things to do prior to the trip. The mailer explained the purpose and features of the My Disney Experience application, how to use the MagicBand, Disney FastPass+, the different Disney parks, as well as an action list for guests to go through prior to the trip.

\subsubsection{Snapchat and Bitmoji}

Bitmoji is an application that allows users to create a 'Bitmoji' character of themselves on their mobile device. Bitmoji characters originally evolved from emojis. The word emoji is an English adaptation of the Japanese word - 'e' meaning picture and 'moji' meaning 'letter, character' (Danesi, 2016). Emojis are usually small pictograms of a face, depicting different emotions in order for users to show how they are feeling in a simple image. The rise of iPhones and Facebook has made emojis much more popularized in recent days, even though the first emojis were created in 1998 (Danesi, 2016). Bitmoji customizes the faces and look of the emojis and can be used in various areas like short-message-service (SMS) and Facebook, but is primarily used in Snapchat. When Bitmoji was purchased from Snapchat in 2015, it was not in any top 10 application markets, but in 2017 it grew in popularity, becoming the number 1 mostdownloaded application in five markets: the U.S., the U.K., France, Canada, and Australia (Molla, 2017). Although Bitmoji can be used outside of the Snapchat these were not taken into consideration for the purposes of the research.

\subsection{Avatars}

An avatar is the digital representation of a user used in digital applications, often designed by the user themselves. It is used to represent the same user in the digital space. There are primarily two different kinds of avatars. The avatar can be a direct representation of the user with the user's likeness, like in Bitmoji or Skyrim, where the user can customize their looks and clothing. Players tend to build avatars that align with their 'ideal selves' (Duchenaut, Wen, Yee, \& Wadley, 2009). The second kind is one where the user plays as an existing character in that universe that the player represents - for example, playing as Lara Croft in the Lara Croft video games. They do not get to

\footnotetext{
${ }^{5}$ (Disney, My Disney Experience Mobile Application, 2017).
} 
choose how to customize their character - instead, they are becoming that character. Some of these systems will allow the user to make changes to their avatar as they gain new gear and equipment, while others stay relatively static for the entire game. For the purposes of this paper, the focus will be on the first type of avatar where users get to choose how they look and determine their clothing, style, and appearance. This can create a stronger bond between the user and their avatar, as they will often make the avatar as a reflection of themselves. Avatars are often seen as one of the three parts of identity - real-world identity, virtual identity, and projective identity (Gee, 2000). In the use of an avatar, there is the real-world identity that is present as well as the virtual identity that the user acts out. The process of identity does not simply end at the creation screen though; it goes far beyond that (Boudreau, 2007). There are other factors that affect identity. Identity is intrinsically tied to historical, institutional, and sociocultural forces (Gee, 2000). The type of avatar and the purpose for the avatar to be created will depend on the environment that the avatar is used for.

\subsubsection{Avatar Creation Process}

There are many existing avatar systems that allow users to create their own avatar - by taking a deeper look into a few to see how they function, the options they have, and the user experience, better understanding can be had about the benefits and limitations. The first to be examined in this research paper is the Bitmoji application for mobile devices. The second is Disney Emoji Blitz's Emojifi me application for web browsers. More complex systems like in Skyrim or The Sims were not explored as they require significantly more time to create than Bitmoji and Disney Emoji Blitz, and the focus is on shorter, less permanent avatars. By giving a player the power to personalize their avatar, this leads to players identifying more closely with the game, as well as take ownership of themselves in the game (Ondrejka, 2004). Klimmt, Hefner, \& Vorderer also recognized that customization amplifies the identification with the character, and therefore, increases enjoyment of the game (2009). When a user can actually see themselves as the avatar, they enjoy the game more fully.

In general, a user has the option to first customize their facial features followed by clothing options. If the avatar system is particularly robust, there may also be options to customize body shape, size, and the height of the character as well. 


\subsubsection{Bitmoji Avatars}

Figure 5a illustrates what the Bitmoji face creation screen looks like. Users have the option to pick a hairstyle on the current page, while the left and right arrows give more options for users to change other details like eyebrows, eyes, nose, mouth and ears. There is no discernable order to the way the facial features are organized; instead, users must scroll through the options if they want to look at the different features.

Figure $5 b$ illustrates how users can scroll through the different clothing options, sorted by the style of clothing. The order of the categories are also not in any discernable order, making it difficult for users to determine what categories follow the next. By clicking on any of the clothing options, it navigates the next screen (Figures 6c). Figures 6c shows how users can scroll left and right to see their avatar dressed in the clothing options.

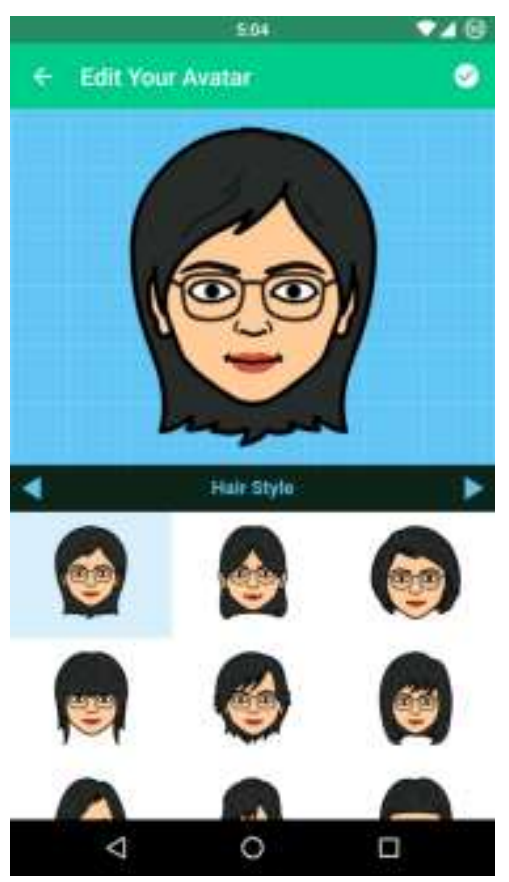

Figures 6a: Bitmoji Face Creation

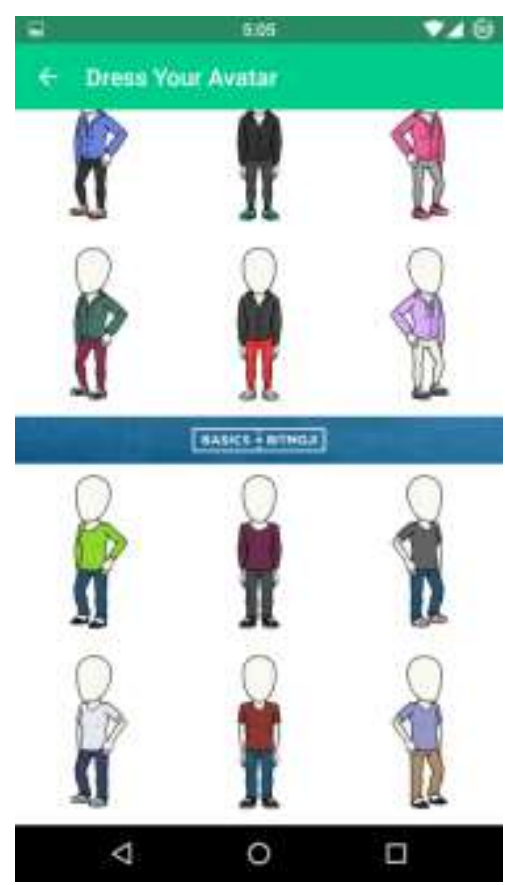

Figures 6b: Bitmoji Clothing Selection

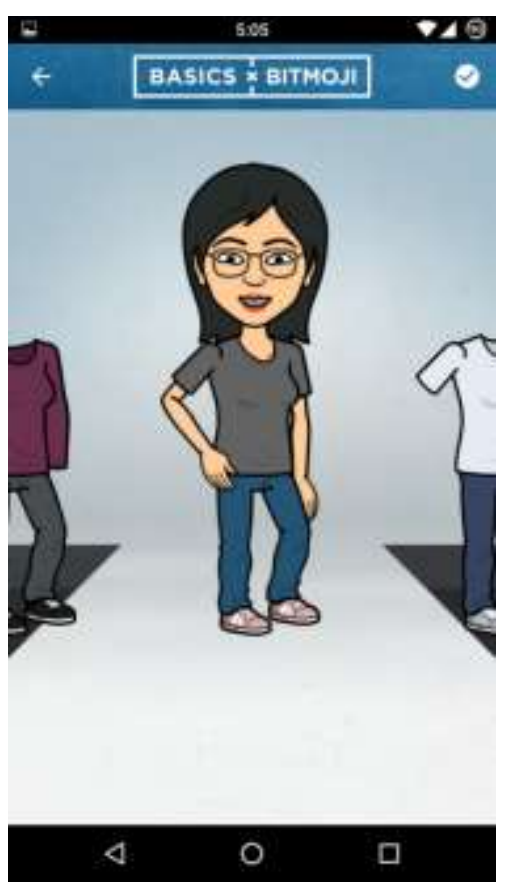

Figures 6c: Bitmoji Dress Up

Figures 6: Creating your Bitmoji Character ${ }^{6}$

\footnotetext{
${ }^{6}$ (Snap Inc, 2017)
} 
Once dressed, users can view the avatar in different expressions and emojis, illustrating the different options to use them in different applications (Figures 7a). There are some special Bitmojis also featured here that may not be available in the different applications. Figures 7b shows Bitmoji avatars being used in a Snapchat conversation. Figures 7c shows how to users can choose different members of the group to respond to, illustrating the social aspect of Snapchat.

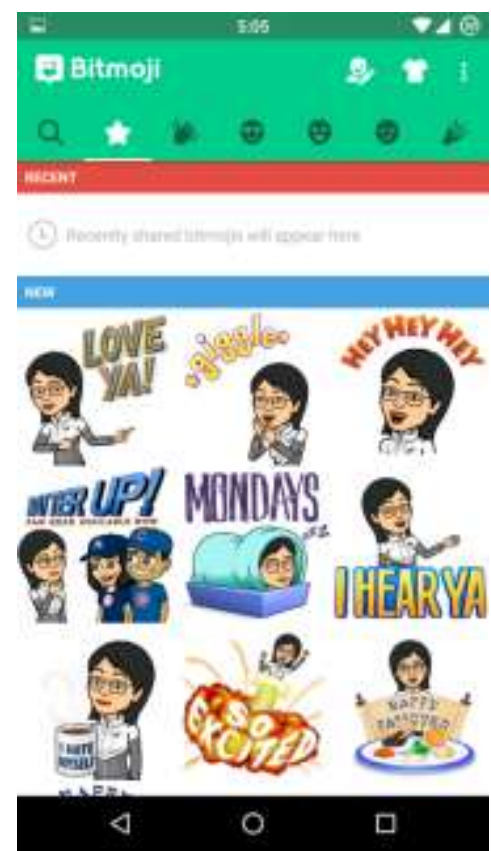

Figures 7a: Bitmoji Options

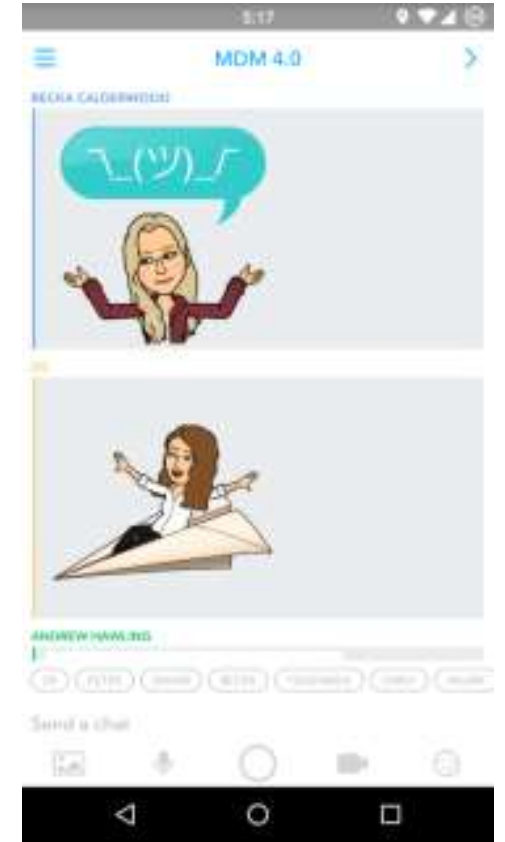

Figures 7b: Bitmoji Snapchat Conversation $^{8}$

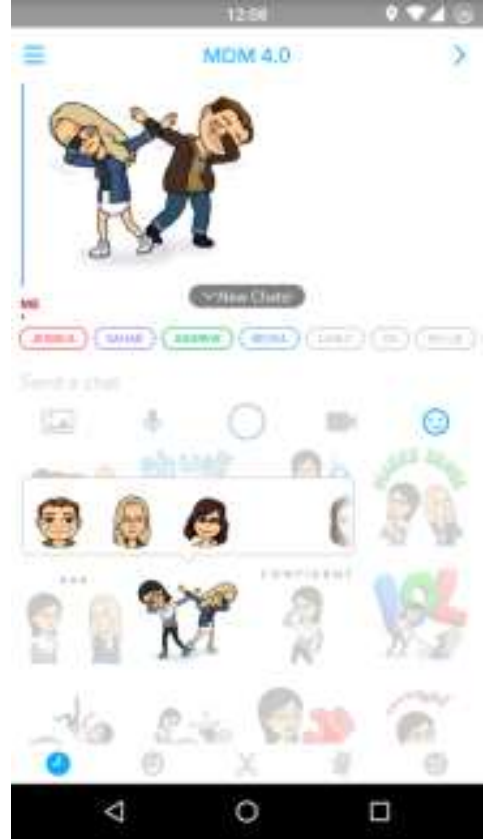

Figures 7c: Bitmoji Group Conversation $^{9}$

Figures 7: Using a Bitmoji Character

One of the largest limitations of the Bitmoji system is the lack of ability to look through the different options easily or in a meaningful way. Since all hairstyles, eyes, and clothing pieces are not organized in any particular order (with the exception of a designer or company paying more money to appear closer to the top), this makes it difficult for users to find pieces of clothing that they may want their Bitmoji to wear without scrolling through the entire list. Another issue is that it is impossible to actual know that there are more items to see unless you already know to scroll down. Bitmoji's parent company, Snapchat, also suffers from a bad user interface - in fact, Snapchat themselves has admitted that their products are confusing to use (Griffith, 2017, and Statt, 2016).

\footnotetext{
7 (Bitstrips, 2017).

8 (Snap Inc, 2017)

9 (Snap Inc, 2017)
} 
In addition, although though Figure $6 \mathrm{c}$ attempts to show the user how their Bitmoji may actually look in the outfit, it is not until after a user has selected the item of clothing they wish to wear that they can see what it looks like in action (Figure 5c and Figure 6a). Yet another limitation of the Bitmoji system is that you cannot see how many steps still remain when you create your avatar. This is reminiscent of the ideal queue that Maister wrote how "uncertain waits are longer than known, finite waits" (Maister, 2005 , p. 5). Similarly, the experience in creating the Bitmoji is less than ideal because there is an uncertain amount of time for the user to finish creating their avatar.

\subsubsection{Disney - Emojify Me}

Although the Emojify Me portion is not actually a part of the actual game, Disney Emoji Blitz, there is an option for users to recreate themselves as an emoji character in the same style as the emojis in the game. This application is purely made for selfenjoyment. There are no actual functions of these emojis. These avatars are made on through a web browser.

Disney Emoji Blitz does not include outfits, and instead is just an emoji face, unlike Bitmoji. Figures 8a illustrates how Disney Emoji Blitz shows the future steps as well as the current step of customization. Figures $8 \mathrm{~b}$ shows the arrows on the left and right of the options to indicate that there are further options. Figures 8c how users can choose an emoji emotion instead of using a typical smiley face. Figures $8 \mathrm{~d}$ is the final screen after a user has finished creating their emoji.

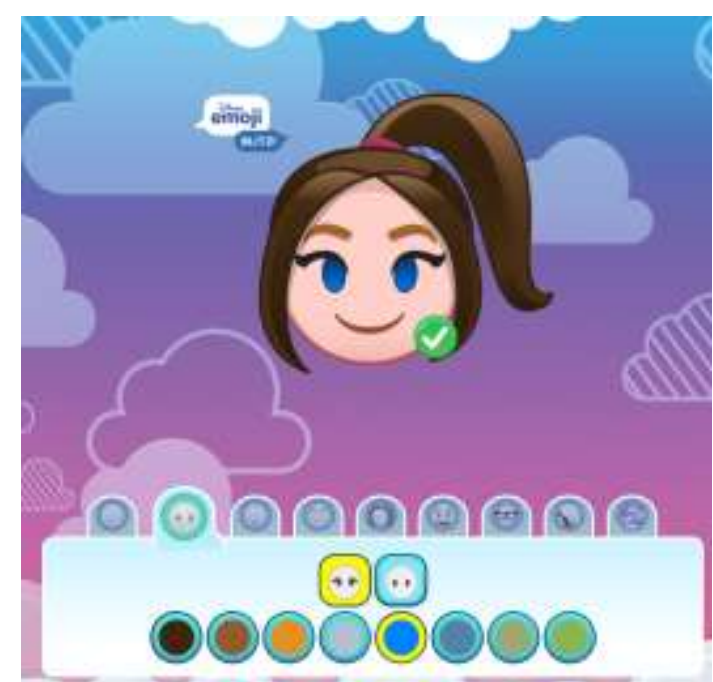

Figures 8a: Disney Emojify Me Face Creation

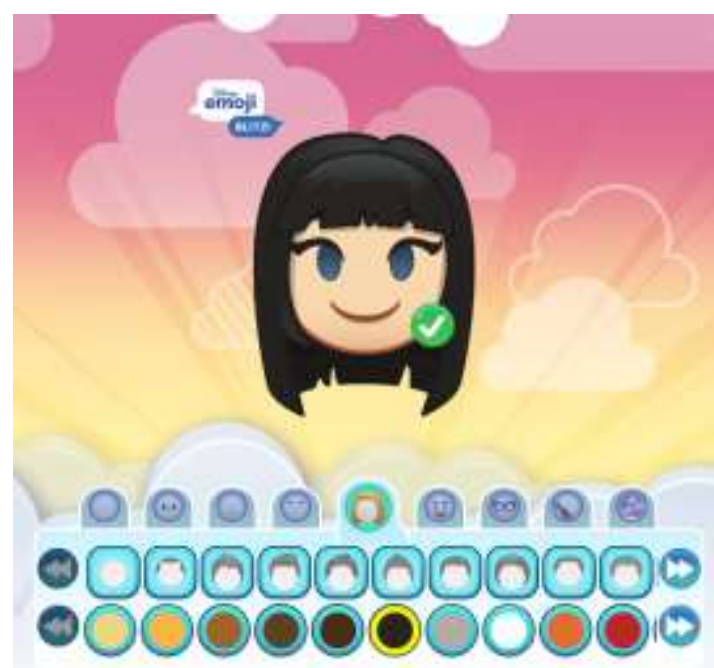

Figures 8b: Disney Emojify Me Hair Selection 


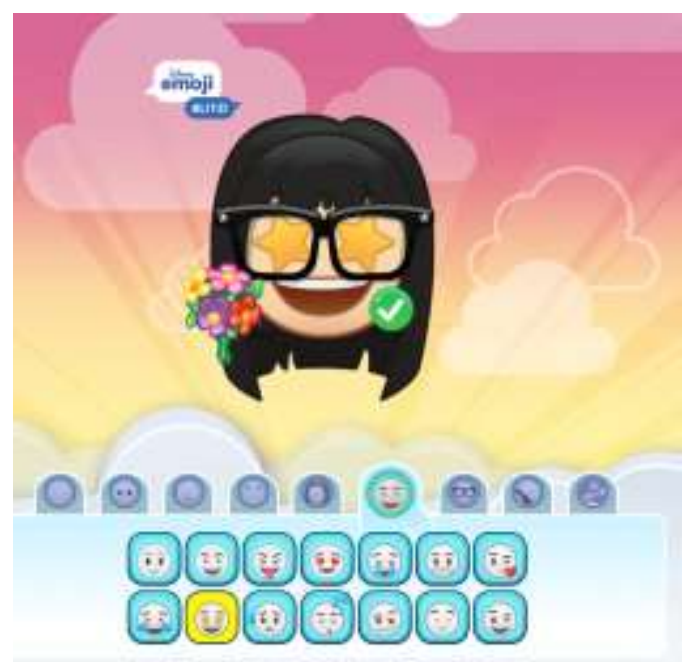

Figures 8c: Disney Emojify Me Emoji Expressions

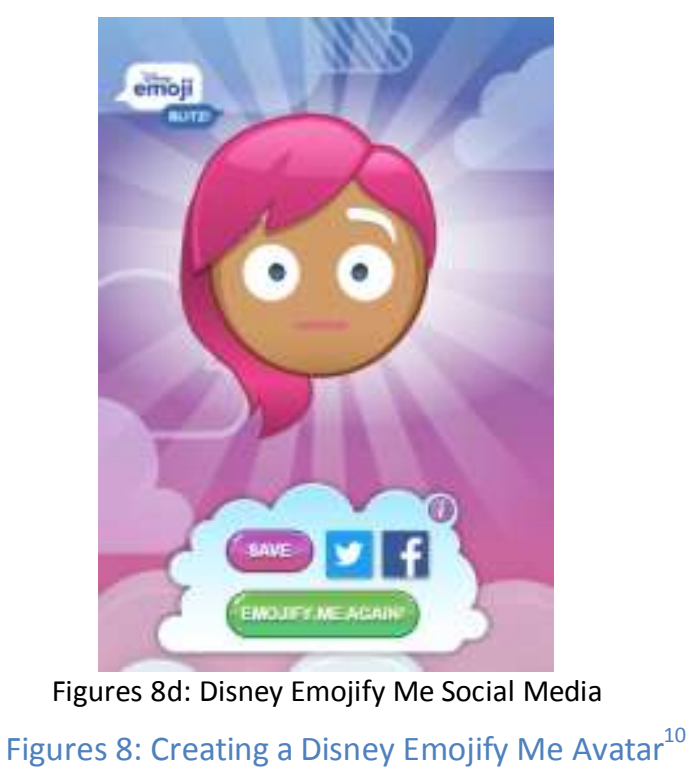

Figures 8: Creating a Disney Emojify Me Avatar ${ }^{10}$

The biggest limitation of the Disney Emoji Blitz Emojify Me system is obviously the lack of options other than facial features. Since it was designed specifically for facial emojis in mind, this limitation is part of its design.

There is no use or interaction after creating the Emojify Me avatar. Users have the options of saving or sharing their emoji as seen in Figure $6 \mathrm{~d}$ but without any real functionality for the emoji, there is no real motivation for a guest to use the system unless they have self-motivation and drive to create an emoji.

Both Bitmoji and Disney Emojify Me are designed to be quick, interactive avatar creators that allow users to make a digital representation of themselves for mobile. While Snapchat has added functionality of usage in other applications, they are not interactive - users have to choose from a pre-set list of emotions and expressions.

\subsubsection{Self-Identification with Your Avatar}

After a user has created their avatar, they tend to identify with said avatar. Since identities are discovered by knowing both what you are, and what you are not, Waggoner believes that users are able to identify with their avatars through this act of merger and division (2009). In cinema, audiences root for characters, and imagine what they would do in their situation. With digital games they become these characters instead and actually decide what to do in these situations. Waggoner also asks what makes something integral to identity, whether it is the individual's choice or society's and comes to the conclusion that identity comes from personal self-awareness, creating

\footnotetext{
${ }^{10}$ (Disney Emoji Maker, n.d.)
} 
a performative aspect to identity (2009). Since there is no performative aspect in films, where viewers take on a passive role instead and so viewers identify less with movie characters than with video game characters. The active role that players have in games actually changes the way a user identifies with the main characters. Thus, when an avatar is created specifically to look like the user, the user identifies even more with the avatar. When they get to actively choose how to act and what actions to take, they will identify with the avatar more than if they have not. Identification is a mechanism which the user can experience an event as if it is happening to them (Cohen, 2001). Thus, when a user creates their avatar and identifies with their avatar, they are experiencing the event themselves - not just their avatar on screen. When the user identifies with their avatar, they are imagining themselves as the character on screen, and that they have a role within the digital world (Cohen, 2001). In addition, identification with the avatar is likely to increase enjoyment, involvement, and intense emotional responses (Cohen, 2001).

Once created, a user decides how to behave in the digital space. Research suggests that individuals are more likely to behave in a manner similar to their everyday self in virtual experiences (Usoh, Alberto, \& Slater, 1996). Thus, if they generally follow rules and laws normally, then they will be more likely to act according to the rules when in a digital space - in chat rooms, digital worlds, etc. The reason is that people feel accountability for themselves - since the avatar is standing in place for them, they feel the desire to be accountable, even to a digital world where it may not actually matter. In addition, decisions made by users are determined by the degree to which they feel compelled by what they experience, and therefore, how immersed they feel in the virtual world (Usoh et al., 1996). The more persuasive the world is, and the more motivation that a system gives a user makes them feel more willing to participate in the world. When acting in a digital world, as is with anything else, the user expects some sort of response that their actions have actually affected the world around them. There is a need for proprioceptive feedback in order to create closed feedback loop and a system that makes sense to the user (Usoh et al., 1996).

\subsubsection{Motivations for Use of an Avatar}

The purpose for creating avatars is for the user to be able to imagine themselves in the digital space, and give them the ability to do whatever they choose. However, 
entering a virtual world is not only about having power, but about "fulfilling your wishes" as well (Ryan, 1999). This empowerment is part of the reason that people turn to games in order to escape - they do not have the same sort of power in their reality. By entering a game as an avatar and donning that identity, they are able to become someone else, someone who has the ability to change the world around them. In addition, by giving users a goal and purpose in the game, this can actually impact the player's personal identity (Boudreau, 2007).

Kirschner and Williams' developed a method to measure players' engagement with digital games through interaction (2014). According to them, because "gameplay is not just an activity, but part of an interactive process through which players negotiate knowledge, competencies, and a sense of self", it is important to understand the process before and after gameplay (2014). Thus, the use of an avatar encapsulates the entire experience; the process of creating the avatar, the actual gameplay and interaction, as well as the processes afterwards. Their data was organized into different levels - the record of the player's actions, the context and reasoning behind the actions, the review of the gameplay, and finally, their analysis of said data. These abstractions allowed Kirschner and Williams to conclude that digital game engagement involves five parts: challenge, control, immersion, interest, and purpose (2014). Each of these five parts are important in game development - without any single part, the motivation for the player falls apart. They also argue that players with varying levels of expertise engage with the game differently, and have a different motivation of playing (2014). This is also true as players who have played the previous game in a series, or have familiarity with the lore of the game will perceive different aspects differently. This is similar to how guests who enter a ride queue who have seen the IP prior to the ride will appreciate the props and scenery differently than someone who has never seen the original source material. Furthermore, this also applies to how some guests who have ridden another version of the ride are "collecting an experience", while others may just be experiencing it because they heard that it was a good ride - their motivations for riding the attraction are completely dependent on their past experiences.

Often, users will flock to using systems that their friends are already using - this is clear even with the very words "social media". The purpose to be social with your friends - without the social aspect, there would be little reason for a user to use that system. However, users that create avatars in online games can also create new 
communities. In Cyan World's game, Uru: Beyond Myst, players can create avatars in order to solve puzzles and uncover the story. After a disappointing release and, according to Cyan Worlds, a lack of players, the Uru servers were scheduled to shut down. Prior to the shutdown process, players gathered in a circular configuration so that their avatars would appear to be holding hands. Immediately following the shutdown, a number of players flocked to a forum, collectively mourning the loss of their game space, with many describing symptoms of posttraumatic stress (Pearce, 2009). The digital community moved beyond just the digital space and instead, had penetrated the real life for the users, manifesting in grief in the loss of the servers and what many users called their homeland. Eventually, past Uru players migrated to another game, There.com, where they created new avatars, and eventually, a new community for themselves. The deep connection formed between the players and their avatars and online community suggests that they can actually form sustainable longterm connections. Boudreau also suggests that this is the case as social and collective identities are defined as shared meanings among a group of individuals (2007). Identity is a necessity in order to instill a sense of meaning and a sense of being within a community (Bauman, 2004).

\subsection{Wearable Applications}

\subsubsection{Disney MagicBand}

As a part of Disney's ecosystem in the Orlando park, Disney rolled out a 1 billion dollar wristband device known as the Disney MagicBand in 2013 (Kuang, 2015). The purpose of the MagicBand is to create a seamless user experience for the guests. The wristband includes a RFID chip that is linked to each guest's account, allowing guests to pre-set things like meal preferences, or health concerns, as well as allowing them to use the MagicBand as their park ticket or for payment in retail stores. In fact, if guests have received the MagicBand prior to the trip, they can even use it to board the Magical Express which connects the airport to the Disney resort. The MagicBand's radio chip allows Disney to know exactly when a guest arrives in a restaurant, and therefore, can begin preparing the guests' pre-selected food choices as soon as they walk in. Guests do not have to deal with menus, or having to order food, instead, they can just directly proceed to their seat and looking at and interacting with the decor. These wristbands 
are available for any Walt Disney World annual passholders, as well as any guests who stay in a Disney Resort. The wristbands are also used as the resort keys and for the FastPass+ system.

\subsubsection{Universal's TapuTapu}

Universal Studios has also implemented their own version of the MagicBand called TapuTapu specifically for their Volcano Bay waterpark. Similar to the MagicBand, TapuTapu connects a guest's profile and payment information to a wristband so that guests do not need to bring their wallet. This device is one of the most recent developments in wristband technologies in theme parks. Similar to the other devices, it allows guests to pay for purchases and save photos to a digital account, as well as open guest lockers. However, its main functionality is quite different from Disney's MagicBand. TapuTapu allows a guest to arrive at an attraction and 'tap on' to the attraction. This means that the guest has now entered a virtual queue for the ride. Once tapped onto a ride, the guest now has the ability to enjoy the wave pool, the lazy river ride (which is hop-on, hop-off style), or lounge around the beach, enjoying scenery. Once it has reached their turn in the virtual queue, the wristband will vibrate, notifying guests that it is their turn to actually ride the attraction that they had tapped onto earlier. This means that guests spend far less, if any, time waiting in the queues as they are enjoying other activities instead. Guests are only able to tap onto one ride at a time, and once they have enjoyed their ride, are able to tap onto other rides and repeat the process. It utilizes an RFID chip and a touch-screen high resolution LCD display protected by Gorilla Glass (Orlando Informer, n.d.).

\subsubsection{Accesso Products}

Accesso, formerly known as Lo-Q is a technology company that creates solutions for the leisure and entertainment markets. Lo-Q has several different products designed specifically for virtual queuing. Universal's TapuTapu uses the newest implementation: the accesso Prism. Prism includes an RFID chip for contactless payments, notifications and a touchscreen interface. Figure 9 illustrates the Prism in an exploded view which includes a glass lens, an LCD display, a waterproof seal, as well as a vibration notification motor. 


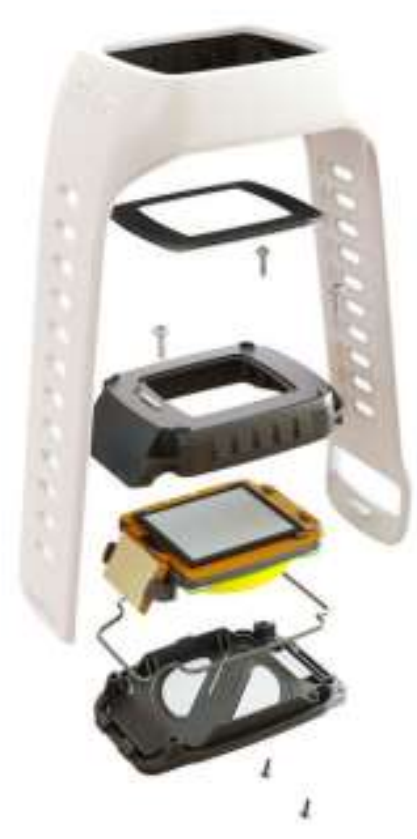

Figure 9: Exploded View of TapuTapu ${ }^{11}$

\subsubsection{Hong Kong's Octopus Card}

Although the Octopus card is outside of the theme park industry, it is still a valuable piece to investigate because of its mass adoption and implementation throughout the entire city of Hong Kong. The Octopus card is a contactless smart card used for making payments for retail, transportation, and point-of-sale purchases. At the moment, there are over 33 million Octopus cards in circulation, and over 99\% of Hong Kong people aged 15-64 possess an Octopus card (Acorn Marketing \& Research Consultants (International), 2016). The Octopus is considered the world's leading complex automatic fare collection and contactless smartcard payment system, having won the Chairman's Award of the World Information Technology and Services Alliance's 2006 Global IT Excellence Award. This city-wide adoption is due to its flexibility in use for all types of retail businesses. In the context of theme parks, it is important that the system is implemented through all of the retail stores in order to ensure high adoption from guests. Octopus Cards Limited also sells watches, keychains, and phone covers that also function as Octopus cards. This is similar to how Disney created a keychain fob option for the MagicBand for guests who do not want to wear a wristband.

\footnotetext{
${ }^{11}$ (Accesso, n.d.)
} 


\subsection{Opportunities for Development}

Theme parks have to find a method in order to satisfy the guests' desires to ride the attraction, allocate ride vehicles in a fair manner, while also crafting the preshow and backstory of the attraction. Presently, theme parks attempt to fulfill these needs and mitigate the tedium of queuing, while also exploring ways to shorten the actual wait time. The queue is an underused area of the park that could be used to enhance the guest experience, as well as encourage and increase guest engagement. Previous attempts of playing games in a virtual queue are not as successful as they can be because the guest only uses a temporary character to play the game. Although a bond could be made with the character they use in the queue, this is only a temporary connection that is lost after they have left the queue. Research also shows that there is an emotional connection between a user and their avatar. Customization and long-term interaction drives this emotional bond, as well as identification with said avatar. Finally, implementations of wristband devices in theme parks are currently only being used for practical reasons such as payment or line up services. These digital technologies have not been used to support both storytelling as well as practicality. Although digital technologies have been used as gaming devices, but in order to enhance the engagement of guests in the queue, more insight is needed into how users choose avatars, and how they currently use technologies in the queue. The three main research questions as mentioned in Chapter 1 are, "how can you increase user engagement through the use of avatars in queue lines in a theme park?", "through an avatar system, how can a better user experience and an emotional bond to the park be created, in order to create a more engaging, and valuable experience in the queue", and finally, "how can an avatar system be designed with the end-user in mind by creating motivation for its use?". This research will explore these questions in the following chapters. 


\section{METHOD}

Two methods were used to collect data for the creation of the avatar system. In order to determine how users would customize their avatars, and to understand why users made avatars, the first method was an online survey which covered topics about queuing, Bitmoji, and theme park behavior. This was to determine how users chose what their avatar would look like in addition to what was pleasant about the experience and their motivations for using Bitmoji in the first place. The second portion of the survey was to gain further information about guests and their experiences at theme parks. A question that would provide particular insight into the end result of how a user's avatar looks would be, "Describe the way you look", followed by "Describe the way your Bitmoji looks". This question directly causes the respondents to reflect on their personal image, as well as their avatar.

The second method for collecting data was an on-site observational study at Disney and Universal Studio parks in Florida. This study focused around what guests were doing while waiting in various types of queues, in addition to observing guest interaction with engagement technologies in the queue.

\subsection{Online Survey}

The survey was made up of 26 questions, split into three sections. The first section was about the general demographic information about the respondents. This was to understand the backgrounds of the respondents for the later sections of the survey. The second section is about Bitmoji and Snapchat amd was designed to understand the reason users create their avatars and why they use them. The final section was about theme parks and the use of various line-skipping passes and devices. The full survey is listed in Appendix A. The online survey was created on SurveyMonkeyTM, and approved by the Ryerson Ethics Board. It was sent out through various personal social media channels including Facebook and Twitter. In order to increase the reach of the study, the survey was also advertised on the volunteer section in Kijiji, and two relevant subreddits on Reddit - r/themepark ${ }^{12}$ and r/samplesize ${ }^{13}$.

\footnotetext{
${ }^{12}$ www.reddit.com/r/themepark: A subreddit dedicated for fans of theme parks around the world.

${ }^{13}$ www.reddit.com/r/samplesize: A community dedicated to completing surveys.
} 
The survey was live for 30 days at which point 58 responses were collected. Out of the 58 responses, 3 responses were under the age of 18, and were completely removed from the results.

\subsection{Queue Line Research}

The secondary method of research was an on-site observational study at Walt Disney World and at Universal Studios in Florida. For each park, a specific ride was chosen for observation. The rides chosen were based on the amount of interactive elements in the line (as researched prior to entering the park). Once in line, notes were made in a notebook based on the following criteria:

- The number of guests using mobile devices and for what purposes

- The number of guests looking at the theming and decor of the queue line

- The number of guests taking photos

- The number of guests who are touching or harming the park features (such as railings or barriers)

The criteria was chosen in order to understand what guests do in line at a theme park, and whether more guests choose to entertain themselves through the methods that the theme park implements (decoration, interactive elements, etc.) or through their own means - talking amongst themselves or using their mobile devices. Additionally, notes were made throughout the visit, documenting things that were seen, and unique digital interactions. The dates that I visited the parks took place from July 6-11, 2017. For each ride, the waiting time was recorded (unless FastPass+ was booked in which case this information is not available), as well as the time of day. Out of the 5 parks visited, 16 specific queues were observed (Table 1). 


\begin{tabular}{|c|c|c|}
\hline Location & Name of Attraction & Type of Attraction \\
\hline \multirow{3}{*}{ Disney Epcot } & Soarin' & Ride \\
\hline & Living with the Land & Ride \\
\hline & Fast Track & Ride \\
\hline \multirow{4}{*}{ Disney Animal Kingdom } & Avatar Flight of Passage & Ride \\
\hline & Baloo \& King Louie & $\begin{array}{l}\text { Character Meet \& } \\
\text { Greet }\end{array}$ \\
\hline & Festival of the Lion King & Show \\
\hline & Rivers of Light & Show \\
\hline \multirow{5}{*}{ Disney Magic Kingdom } & Seven Dwarfs Mine Train & Ride \\
\hline & Haunted Mansion & Ride \\
\hline & The Many Adventures of Winnie the Pooh & Ride \\
\hline & Walt Disney's Magical Tiki Room & Show \\
\hline & Space Mountain & Ride \\
\hline \multirow{4}{*}{ Disney Hollywood Studios } & Rock \& Roller Coaster & Ride \\
\hline & Tower of Terror & Ride \\
\hline & Star Tours & Open area \\
\hline & Kylo Ren & $\begin{array}{l}\text { Character Meet \& } \\
\text { Greet }\end{array}$ \\
\hline $\begin{array}{c}\text { Universal Studios' } \\
\text { Volcano Bay }\end{array}$ & General observation of all rides throughout park & Ride \\
\hline Transportation & Disney Magical Express & Video on bus \\
\hline All Star Sports Resort & Lobby area & Open area \\
\hline
\end{tabular}




\section{RESULTS}

\subsection{Survey Results}

Three respondents were under the age of 18, and their answers were completely removed from all of the following results. Although $13 \%$ of the respondents had not been to a theme park in the past 5 years, their responses were still used in the data results as their answers for the theme park section were independent of the Snapchat and Bitmoji sections of the survey.

\subsubsection{Survey Demographic Results}

Out of the 55 responses collected, 53\% respondents identified as male, 43\% female, and $4 \%$ as other (Figure 10 ). The $21-24$ age range consisted of $42 \%$ of the respondents (Figure 11). While the majority of the respondents (35\%) normally use their smartphones to message their friends, specifically in queue lines, respondents used their phone for a variety of reasons, showing that respondents do not use their phones for any singular purpose (Figure 12).

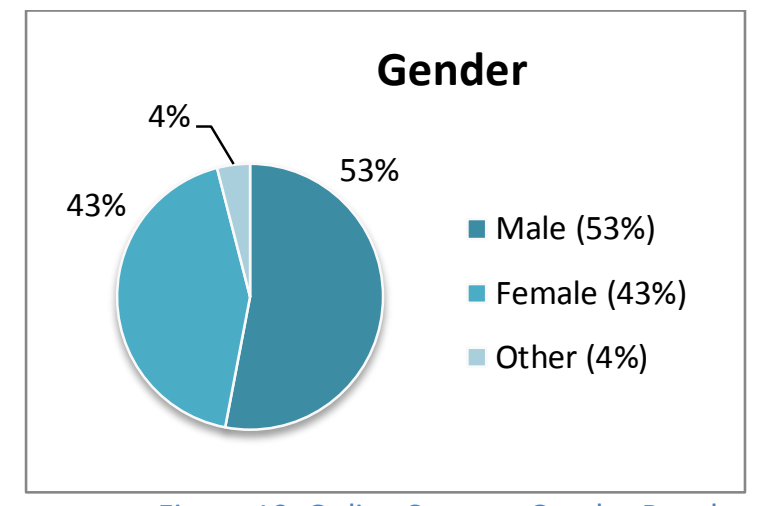

Figure 10: Online Survey - Gender Results

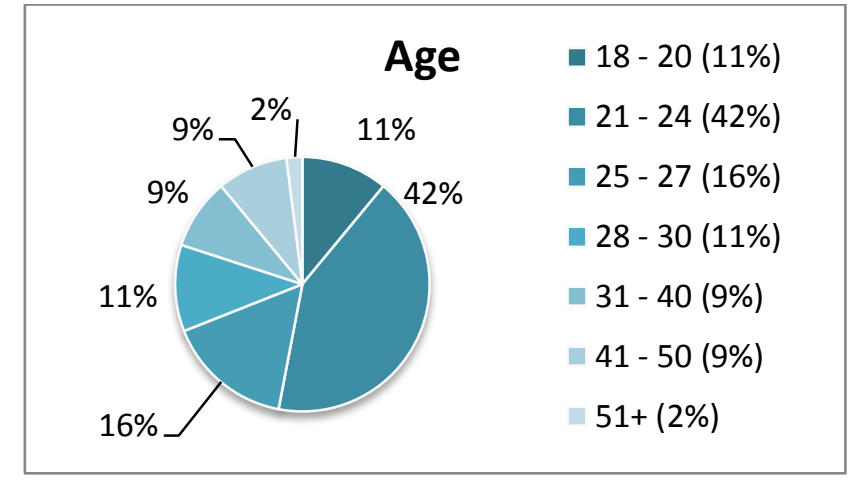

Figure 11: Online Survey - Age Results

\section{What do you normally use your Smartphone for?}

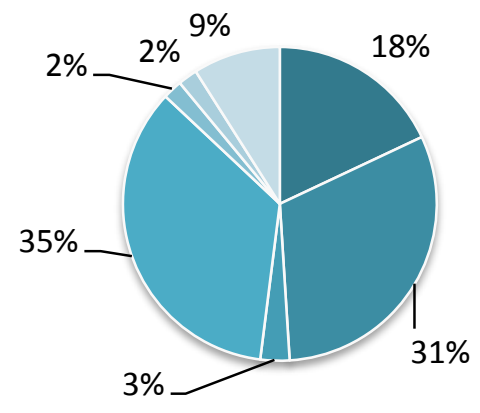

- Read articles/websites on my phone (18\%)

- Browse social media (31\%)

- Play phone games (3\%)

- SMS/Messaging friends (35\%)

- Phoning friends (2\%)

Take photos (2\%)

Other (9\%) 
While only $3 \%$ of respondents normally use their smartphone to play games on a regular basis, in queue lines, $32 \%$ of respondents play games most often, followed by $28 \%$ browsing social media, and $23 \%$ reading articles or websites on their phone (Table 2: Online Survey - Question 4). This indicates that while on a regular basis, users do not play games on their mobile devices; they are more likely to take their devices out to play games in line.

Table 2: Online Survey - Question 4

\begin{tabular}{|c|c|c|c|c|c|c|}
\hline When you wait in lines, what do you normally do? & $\begin{array}{c}1 \\
\text { (Most } \\
\text { often) }\end{array}$ & 2 & 3 & 4 & $\begin{array}{c}5 \\
\text { (Least } \\
\text { often) }\end{array}$ & Average \\
\hline Read articles/websites on my phone & $13 \%$ & $17 \%$ & $26 \%$ & $21 \%$ & $23 \%$ & 3.26 \\
\hline Browse social media & $13 \%$ & $24 \%$ & $20 \%$ & $15 \%$ & $28 \%$ & 3.22 \\
\hline Play phone games & $24 \%$ & $10 \%$ & $15 \%$ & $20 \%$ & $32 \%$ & 3.24 \\
\hline Talk to friends (face to face in line) & $43 \%$ & $13 \%$ & $13 \%$ & $6 \%$ & $26 \%$ & 2.60 \\
\hline Talk to friends (through phone/social media) & $10 \%$ & $20 \%$ & $32 \%$ & $22 \%$ & $17 \%$ & 3.17 \\
\hline Take photos & $9 \%$ & $33 \%$ & $26 \%$ & $14 \%$ & $19 \%$ & 3.00 \\
\hline Day dream/stand quietly/think quietly & $23 \%$ & $23 \%$ & $30 \%$ & $11 \%$ & $13 \%$ & 2.66 \\
\hline
\end{tabular}

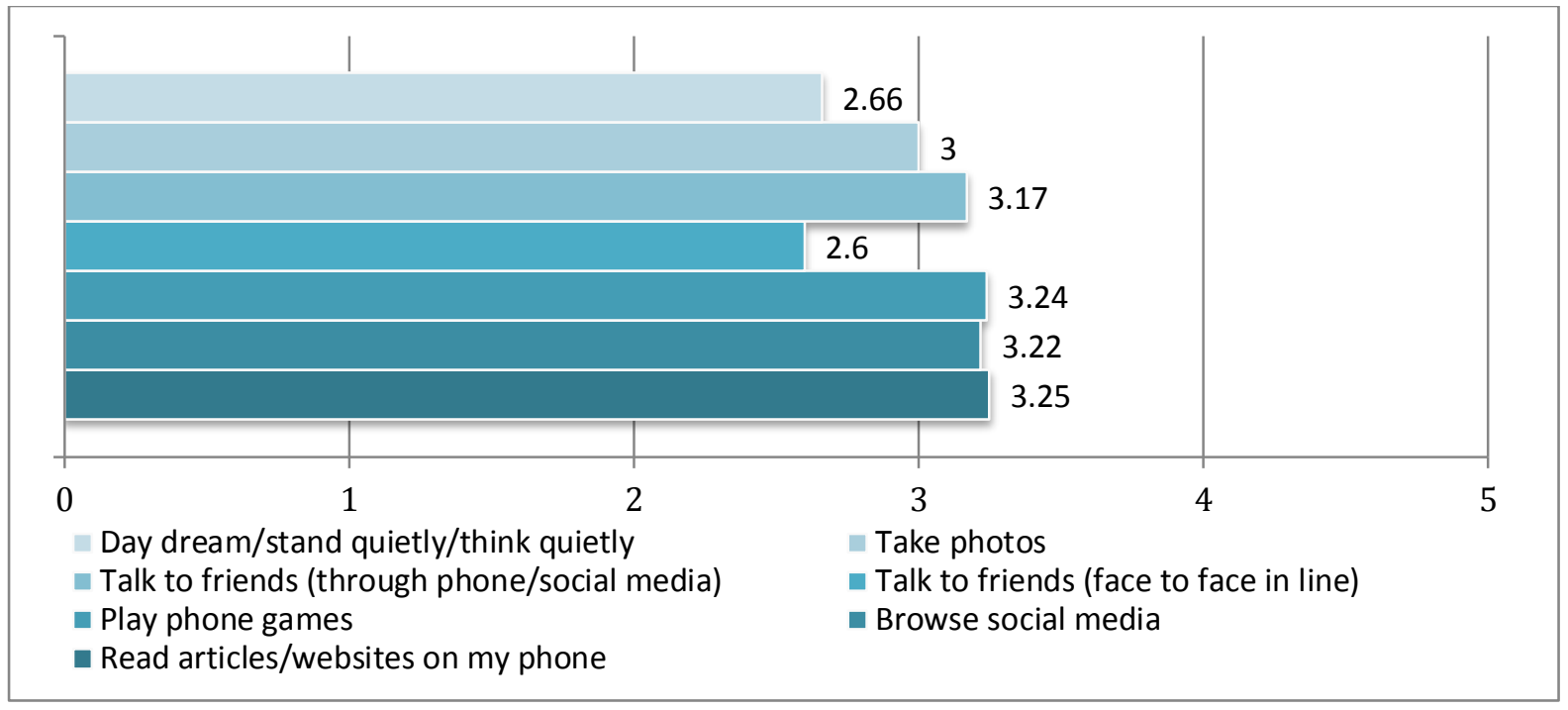

Figure 13: Online Survey - Question 4 Averages

As seen in the data, people do a variety of tasks while in a queue (Table 2 and Figure 13). There is no single activity that respondents do in particular. 


\subsubsection{Survey Snapchat and Bitmoji Results}

Out of the 36 respondents who used Snapchat, 59\% of these respondents used Bitmoji (Figure 14). When creating their Bitmoji avatars, 95\% of users attempted to replicate their own facial features (Figure 15), and while dressing their avatars, 79\% attempted to find something that showed off their real-life personal style (Figure 16). This discrepancy informs that while users tend to replicate their facial features, their actual outfits may differ from their personal style. This reflects similar research showing that users create avatars representing themselves, as well as who they wish they were.

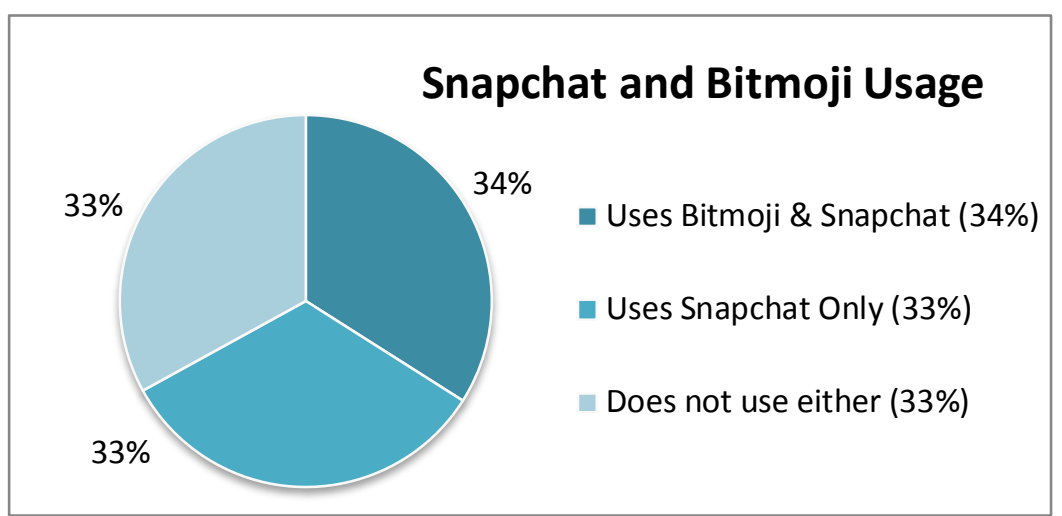

Figure 14: Online Survey - Snapchat and Bitmoji Usage

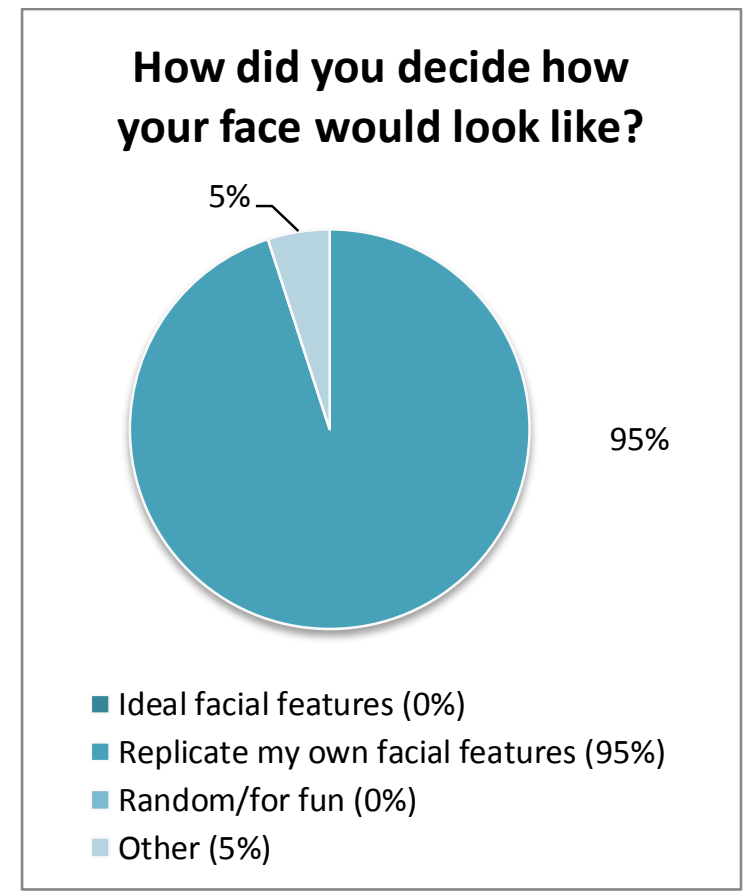

Figure 15: Online Survey - Facial Features

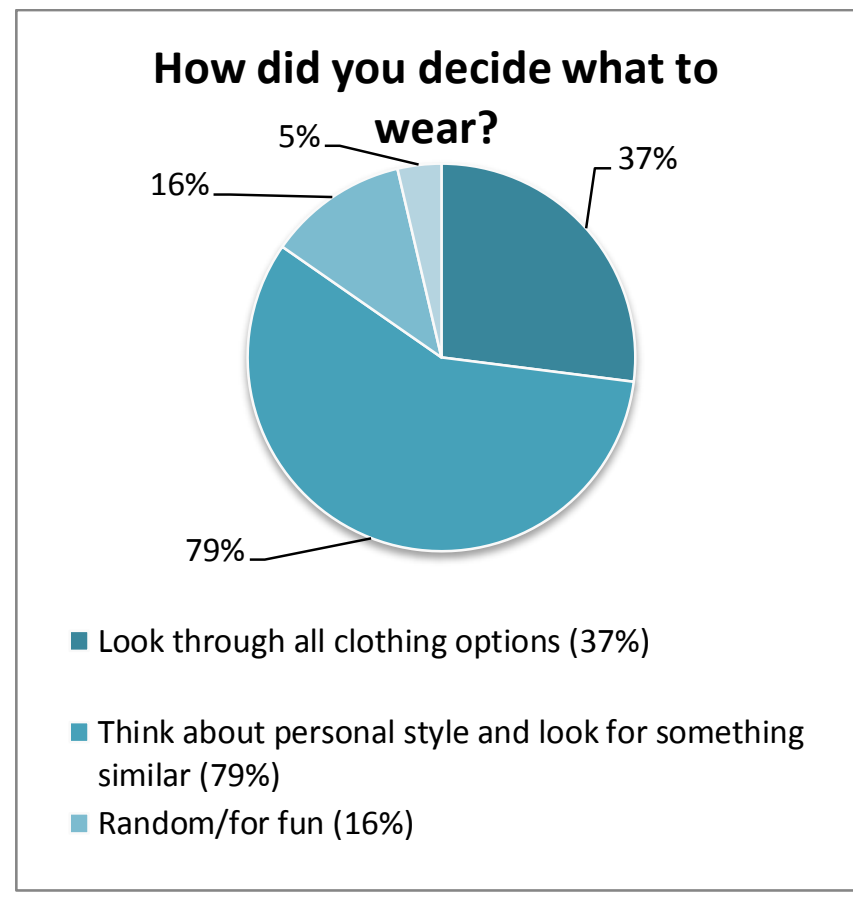

Figure 16: Online Survey - Clothing Options

All of the respondents who responded to the question 14, "Describe the way you look" and question 15, "Describe the way your Bitmoji looks" either copied the same 
description from their first answer to their second answer or simply wrote that it was "same". One respondent claimed that their Bitmoji looked like "a cartoon version of myself" (Table 3). Out of the 13 responses to these questions, 6 responses included a description of their physical build or height, even though Bitmoji does not give users the option to specify that (Table 3). 


\begin{tabular}{|c|c|c|}
\hline $\begin{array}{l}\text { Respondent } \\
\text { Number }\end{array}$ & Q14: Describe the way you look & Q15: Describe the way your Bitmoji looks \\
\hline 5 & Pale, white, brown hair & Pale, white, brown hair \\
\hline 6 & Young, white short brown hair, fat & Young, white short brown hair, fat \\
\hline 15 & $\begin{array}{l}\text { White, blonde, wears makeup and dresses } \\
\text { nicely }\end{array}$ & Same characteristics \\
\hline 16 & Like a human & Like me \\
\hline 17 & Female, brown hair, blue eyes, Caucasian & Female, brown hair, blue eyes, Caucasian \\
\hline 18 & Brown hair, green eyes, very white, beard & Brown hair, green eyes, very white, beard \\
\hline 19 & $\begin{array}{l}\text { Black hair w/ blue ombre, glasses, brown } \\
\text { eyes, tan skin, change clothes from day to } \\
\text { day }\end{array}$ & $\begin{array}{l}\text { Black hair, glasses, brown eyes, similar skin } \\
\text { tone to real life, hair is a little too straight } \\
\text { (not exact same hair cut) }\end{array}$ \\
\hline 20 & $\begin{array}{l}\text { Black hair, brown eyes, olive skin tone, } \\
\text { average build and above average height }\end{array}$ & $\begin{array}{l}\text { My Bitmoji has black hair and brown eyes } \\
\text { with an average build. She's wearing a } \\
\text { raincoat because it's been cold and rainy out } \\
\text { lately }\end{array}$ \\
\hline 25 & $\begin{array}{l}\text { Reddish hair, green eyes, slender build, } \\
\text { medium length hair, jays hat }\end{array}$ & Same \\
\hline 40 & Brown hair, glasses, blue eyes & a cartoon version of myself \\
\hline 41 & $\begin{array}{l}\text { Dirty blonde hair, blue eyes, white skin, } \\
\text { freckles, tall, thin }\end{array}$ & $\begin{array}{l}\text { Dirty blonde hair, blue eyes, white skin, } \\
\text { freckles, thin }\end{array}$ \\
\hline 51 & $\begin{array}{l}\text { Long black hair with a side part, black wide } \\
\text { rimmed glasses, usually no makeup except } \\
\text { eyeliner and some brown eye shadow for } \\
\text { work, either smart casual or a t-shirt and } \\
\text { jeans }\end{array}$ & $\begin{array}{l}\text { Shoulder length black hair with a side part, } \\
\text { black wide rimmed glasses, some brown eye } \\
\text { shadow, casual clothes }\end{array}$ \\
\hline 53 & $\begin{array}{l}\text { Long blonde wavy hair, freckles, athletic } \\
\text { build, green/hazel eyes, wide, somewhat } \\
\text { squinty almond eye shape, long straight } \\
\text { ridged nose with defined and wider nostrils, } \\
\text { very light blonde, straight and skinny } \\
\text { eyebrows, blushed complexion, small lipped } \\
\text { and natural (peach/reddish) toned lips, } \\
\text { brownish /smokey eye shadow }\end{array}$ & $\begin{array}{l}\text { Long blonde wavy hair, freckles, athletic } \\
\text { build, green/hazel eyes, wide, somewhat } \\
\text { squinty almond eye shape, long straight } \\
\text { ridged nose with defined and wider nostrils, } \\
\text { very light blonde, straight and skinny } \\
\text { eyebrows, blushed complexion, small lipped } \\
\text { and natural (peach/reddish) toned lips, } \\
\text { brownish /smokey eye shadow }\end{array}$ \\
\hline 54 & $\begin{array}{l}\text { Chinese, short, medium length hair, dark } \\
\text { brown hair, glasses, apple shape }\end{array}$ & Medium length hair, dark brown hair, glasses \\
\hline 56 & White with black hair & White with black hair \\
\hline
\end{tabular}


Out of the responses to question 12, "Why do you use Bitmoji", 7 respondents used Bitmoji "for fun", while 4 used Bitmoji to "express myself" (Table 4).

Table 4: Online Survey - Responses to Question 12

\begin{tabular}{|c|l|}
$\begin{array}{c}\text { Respondent } \\
\text { Numbers }\end{array}$ & Q12: Why do you use Bitmoji? \\
\hline $2,6,17,20,25,56$ & $\begin{array}{l}\text { "fun in Snapchat" } \\
\text { "more fun than texting" } \\
\text { "fun" } \\
\text { "it's a fun way to interact with friends" } \\
\text { "for fun, sending stickers are sometimes more interesting than plain emojis" } \\
\text { "for fun" } \\
\text { "its fun to use" }\end{array}$ \\
\hline $15,16,32,51$, & $\begin{array}{l}\text { "as a way to express myself" } \\
\text { "to feel like Lizzie McGuire (ie an alternative form of expression)" } \\
\text { "to create a representation of myself" } \\
\text { "to express how I'm feeling with my image" } \\
\text { "to replicate my real-life expressions through digital media when communicating with others" }\end{array}$ \\
\hline
\end{tabular}

Additionally, out of all 19 responses to question 13, "Do any of your friends use Bitmoji?", $100 \%$ of respondent said that their friends did use it. This shows that Bitmoji and Snapchat is inherently linked to the social component - people use Bitmoji when their friends also use it. 


\subsubsection{Survey Theme Park Results}

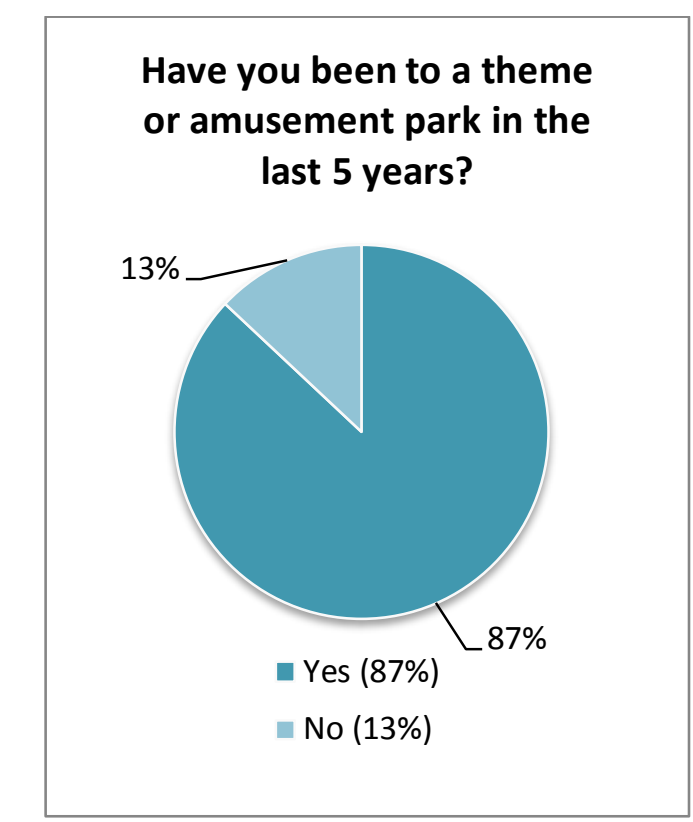

Figure 17: Online Survey - Theme Park Attendee

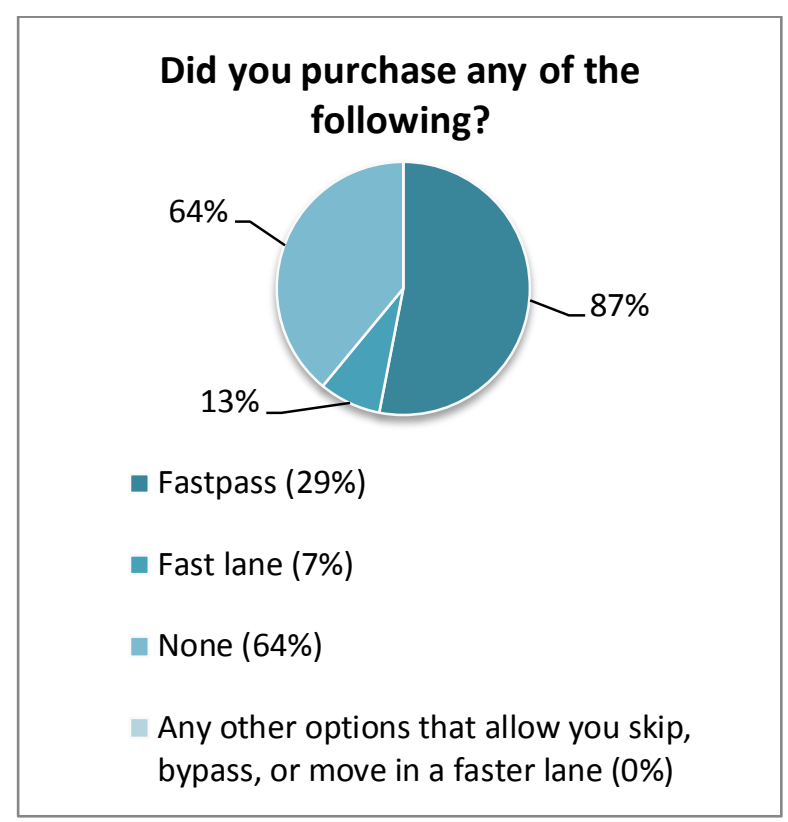

Figure 18: Online Survey - Theme Park Purchases

Out of 52 responses, $87 \%$ of respondents have been to a theme park in the past 5 years (Figure 17). Out of those respondents, 36\% purchased an option from the park that allowed guests to skip, bypass, or move in a faster line than guests who did not (Figure 18).

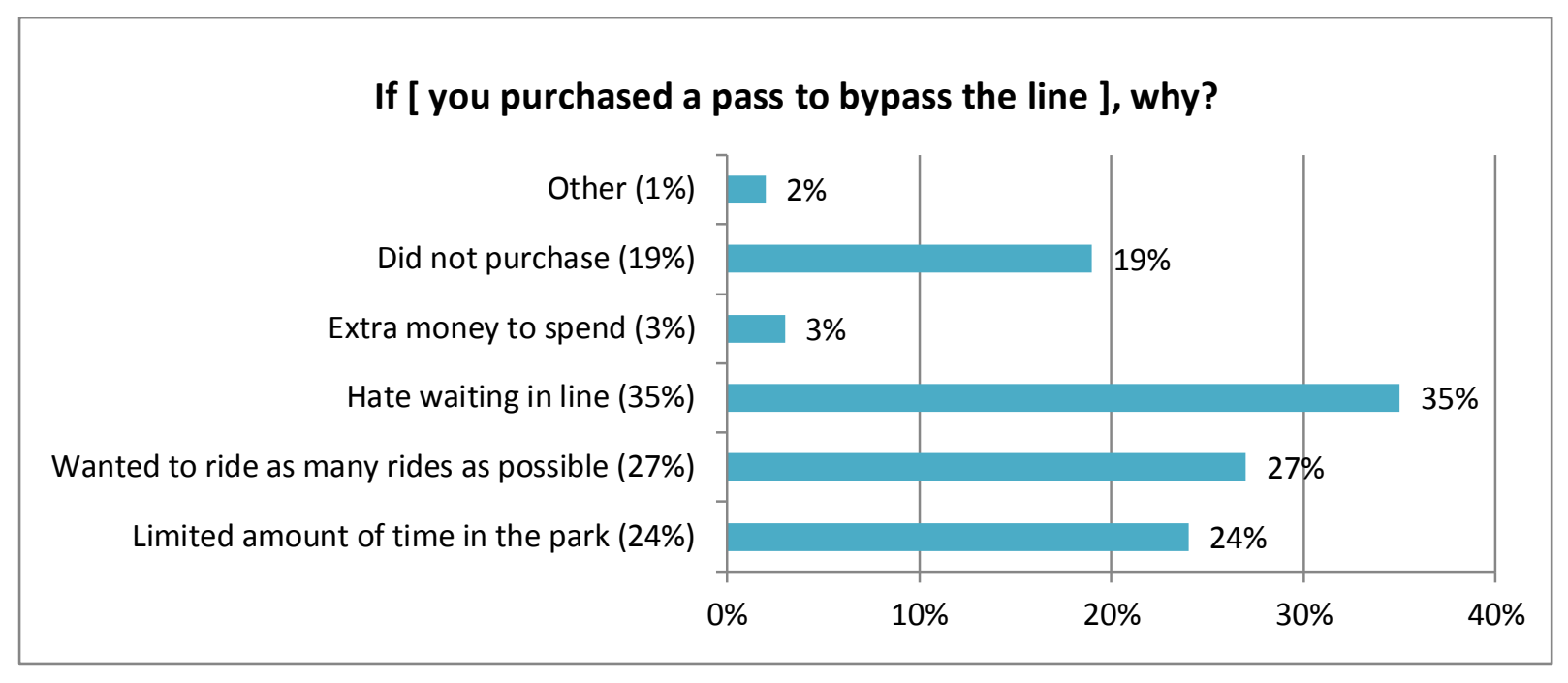

Figure 19: Online Survey - Reason for Purchasing a Pass

Thirty five percent (35\%) of guests purchased said passes because they did not want to wait in line, followed by $27 \%$ who wanted to ride as many rides as possible, and $24 \%$ who had a limited amount of time in the park (Figure 19). Note that the answers 
for this question surpass $100 \%$ as respondents could chose however many answers applied to their situation.

\subsubsection{Disney MagicBand Users}

Out of the respondents, 34\% had used a Disney MagicBand while visiting Walt Disney World (Figure 20). In addition, only 7\% of respondents owned a Disney annual pass (Figure 21). Out of users who used a DisneyMagic band, $85 \%$ used them to enter the park. Disney offers MagicBand users the option to use the PhotoPass when they take photos which links photos directly to the guests' accounts.

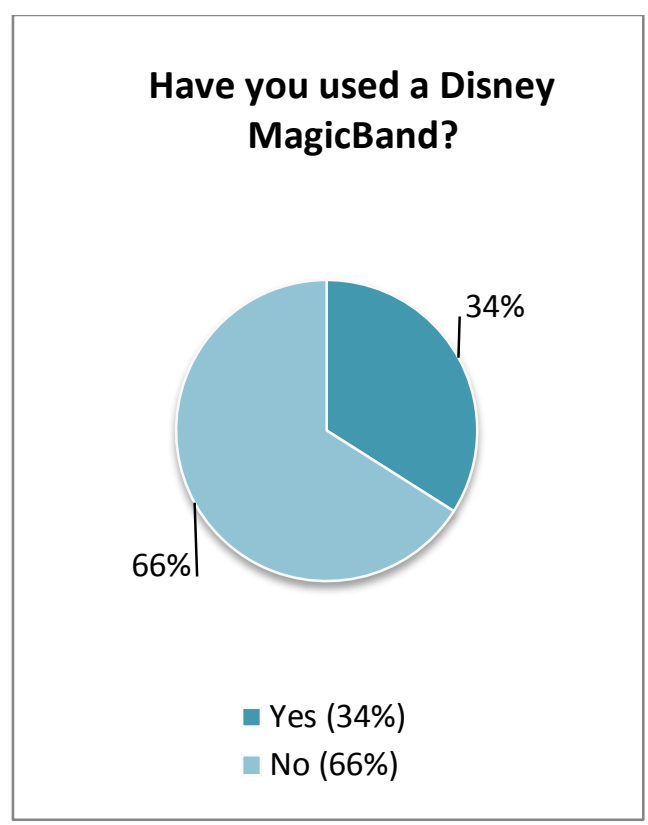

Figure 20: Online Survey - Disney MagicBand Usage

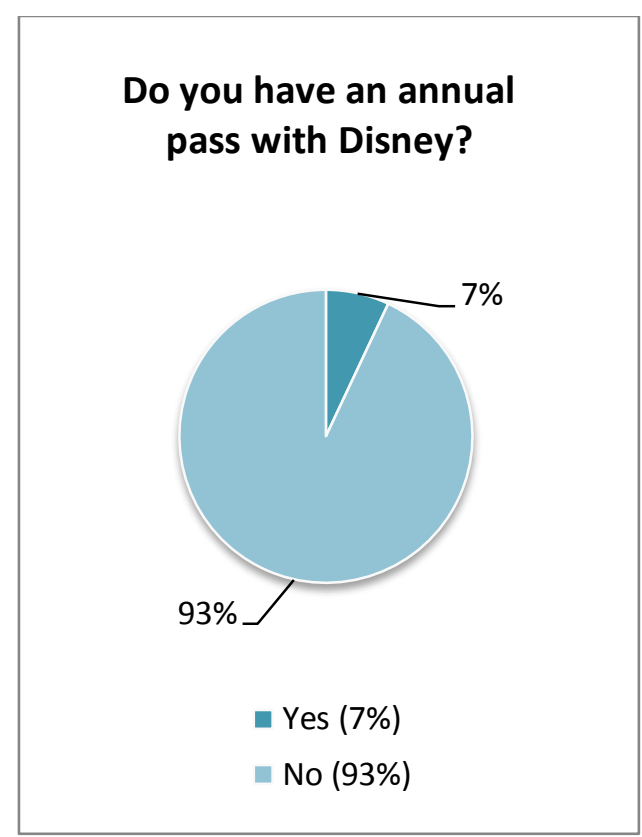

Figure 21: Online Survey - Disney Annual Pass 


\subsection{Queue Line Observational Research}

Three hundred and eighty-three guests were recorded during the site visit. These results were broken down into nine main categories (Figure 22).

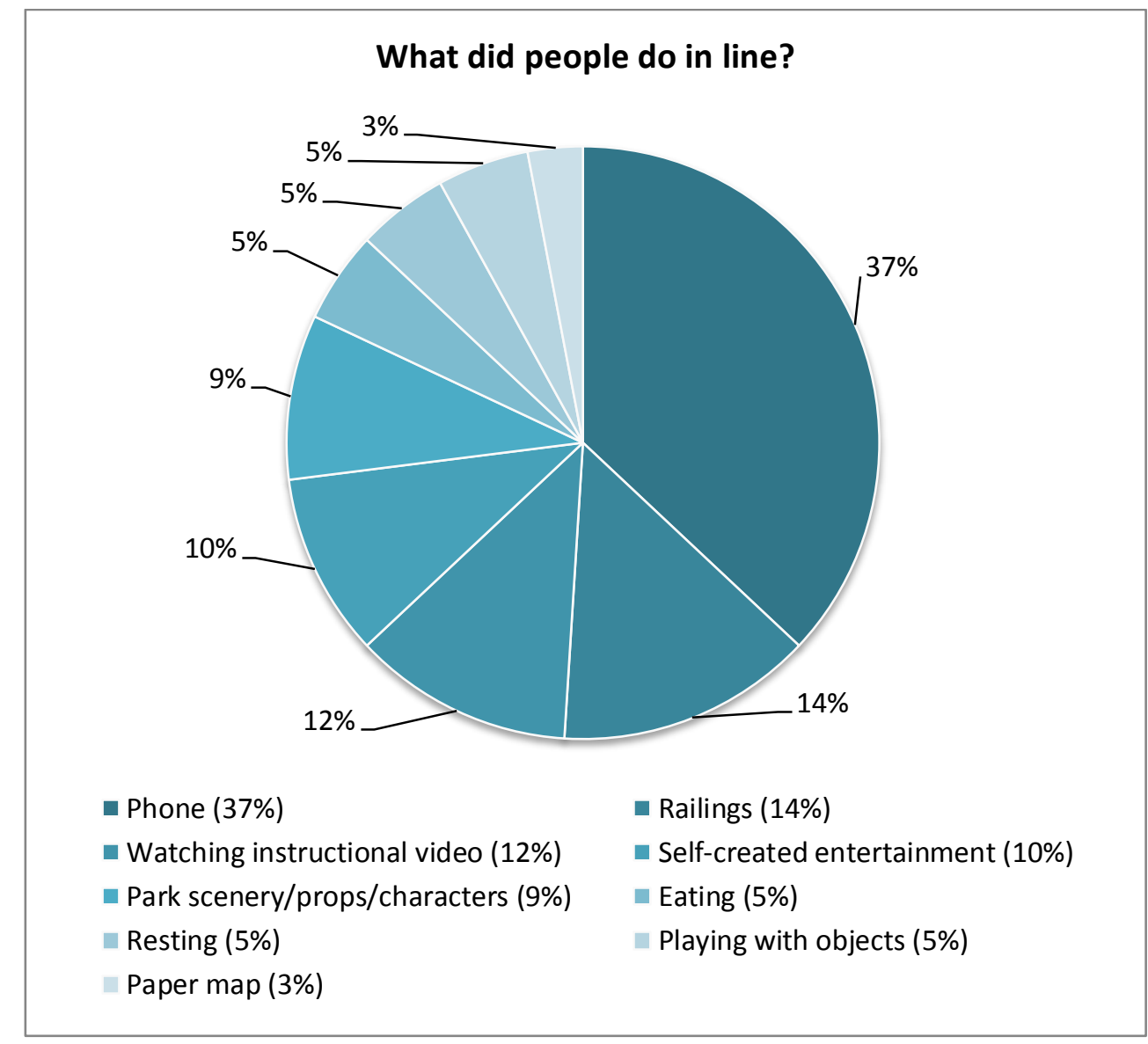

Figure 22: Queue Line Observational Research

The largest majority of guests (37\%) were on their phones in the queue, and $29 \%$ of these guests were actively looking at photos or taking photos. Guests on their phones were using a variety of social media platforms - Facebook and Instagram were the two most popular, although there were also many guests who were on their email or sending messages through various applications.

The railing category was created as separate from the park scenery as guests who were leaning, pulling on, or moving the railings are actually behaving in destructive behavior, while the park category is only observational behavior. The category of selfcreated entertainment included methods that people were passing time without the use of a mobile device.

Only $12 \%$ of guests would watch the instructional video. They were more likely to watch it if the video was the focus of that particular room and close to the entrance of 
the ride. It is important to rides to ensure that guests pay attention to said videos as they often contain important information such as the intensity of the ride, safety information that guests may need to know prior to sitting in the ride vehicle (for example, what and where to store their belongings), and less importantly to the guests, the story behind the ride. This may not account for guests who have already been on the ride and are under the impression that they know the safety features of that ride.

Guests were most likely to interact with the park's entertainment when there were cast members in costumes and actually making a personalized effort to interact with the guests instead of static scenery pieces. Instead, it was found that 38 guests created their own forms of entertainment which included things like fighting with each other, giving massages, braiding their hair, drawing, or playing hand games. This shows that there are guests who attempt to wait in line without resorting to the use of their phones.

\subsubsection{My Disney Experience and Disney MagicBand}

As a guest of the Disney All Star Sports Resort, guests are able to use the Disney MagicBand throughout the parks and resort. Chip readers for RFID cards in the United States are not as widespread as in Canada, and cast members often had to explain to guests to hold the MagicBand against the reader each time they used it.

The MagicBand is a great tool for guests who booked FastPass+ for rides as it allowed cast members to quickly scan each guest to ensure that guests had registered properly and was not trying to skip the line. Additionally, the system was implemented so that even if guests missed the first scan, they were often scanned again later on in the queue to ensure guests did not cheat the system by using a single FastPass+ booking twice. Additionally, the MagicBand made it extremely convenient for guests to pay for both merchandise as well as food. Missing from the My Disney Experience application was a tab that showed all the purchases made with the MagicBand in one easy location.

\subsubsection{Volcano Bay TapuTapu}

As part of the observational study, Universal Studio's new waterpark, Volcano Bay, was also studied in order to study the behavior of guests and the new wearable implementation, TapuTapu. On arrival at the park, there was not very much onboarding to teach guests how to use the TapuTapu band. The only mention was a very brief 
comment from the park operators who were handing out the wearable, as well as a pamphlet that a guest could choose to pick up when they purchased their ticket into the park (Figure 23).
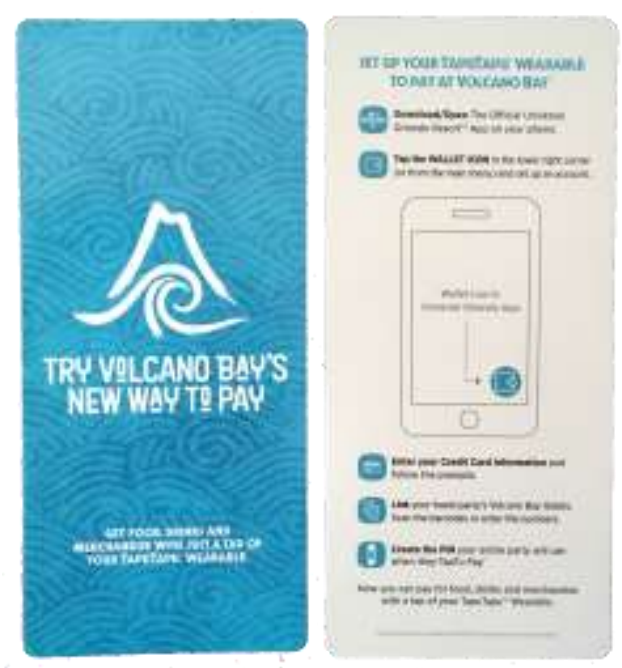

Figure 23: TapuTapu Onboarding Pamphlet ${ }^{14}$

As a result, at many of the rides, there were long lines to tap on the ride as guests did not understand how to use the band in order to reserve their position in line. While the actual use of the band worked flawlessly and very responsively, there were some fundamental issues with the implementation. While at the park, guests were able to tap onto an attraction that had a 270-minute wait. Once the wearable notified the guest that it was their turn to ride they were able to return to the attraction. While in line waiting to actually ride, the attraction broke down completely. There was no compensation for this technical difficulty. All the guests who had tapped on a 270 minute wait had essentially tapped on for no reason and lost their position in line. Guests were seen to be quite angry that they just lost their position in line after waiting more than 270 minutes. Several guests tried to sneak into the other ride that shared the same line up and staircase area. Universal Studios had not yet implemented logic into the system to reserve a guest's position in line if the attraction is shut down.

\footnotetext{
${ }^{14}$ (So, 2017).
} 


\section{DESIGN}

In order to best engage and cultivate an emotional bond between the user and the avatar, it is recommended that an avatar system, known as AvatarMe, be developed as a product, available to parks as a park-wide application in order to enhance and engage guests in the queue. AvatarMe will be part of the pre-park experience, the park experience itself, and in the post-park experience to emulate the ideas of the five E's of user experience: entice, enter, engage, exit, and extend. Users will interact with the system through the use of a mobile device in park, or on a personal computer at home. The avatar system will be linked in a wristband device, tapping onto contact points in order to use the interactive screens and games.

For the purposes of this paper, mock ups and designs have been designed as if designed for Walt Disney World, including costumes and attraction names. Since most readers will already be familiar with the characters and stories, this report will not need to further establish this sample case.

\subsection{Entice}

The entice stage is about pre-park experience that the system will create, in the theme park world, this is the onboarding portion of the attraction. This portion takes place online through a web interface, accessible both through a mobile device and a personal computer. As part of the entice stage, guests will be able to build their personal avatar. Building a visual representation prior to entering the park is important as the visualization is needed in order for guests to actually build a connection with their avatar and "imbue meaning into the actions and interactions of the avatar within the game world" (Boudreau, 2007).

When guests arrive at Disney resorts, the resort hosts will often ask guests if they are celebrating anything special: first visits, birthdays, events, engagements - this could be similarly implemented in the application, giving guests access to special costumes that would not otherwise be available. This would be part of the enticement and motivation for guests to use AvatarMe because of the exclusivity and the limited access they could have to these special costumes. The exclusive costumes would be implemented throughout the system, for holidays and special events like marathons; there would also be costumes that are only accessible during that time period. The 
entice stage is not only at the initial stage of using AvatarMe, but throughout the experience and beginning of each experience in the queue. The continued motivation for guest usage is important for continued usage.

\subsubsection{On-Boarding and Creation Process}

The on-boarding process introduces the idea of the avatar and the game system to the guests prior to them entering the park. This takes place through a mailer as well as an email. The mailer explains the possibilities of using the avatar throughout the park and explains the collectible nature of the costumes and outfits.

As part of the onboarding, the mailer and email would explain and show a guest how they can change their avatar outfits. This is in line with guest behavior about how they want the experience to get started (Maister, 2005). By allowing them to choose from a few costumes at the beginning, they will be able to get a feel of how the system works, give them the motivation to start interact with their avatar in the park, as well as get the experience started. 


\subsubsection{Web Application}

In order for guests to determine how their avatars will look, they will need to login on a web browser in order to dress their avatar. This system can be accessed both on a mobile device as well as a computer, giving the guest flexibility on where they would like to customize their avatars. This system also allows them to explore unearned outfits and accessories in order to keep in mind which rides or attractions they may want to visit in order to collect those outfits.

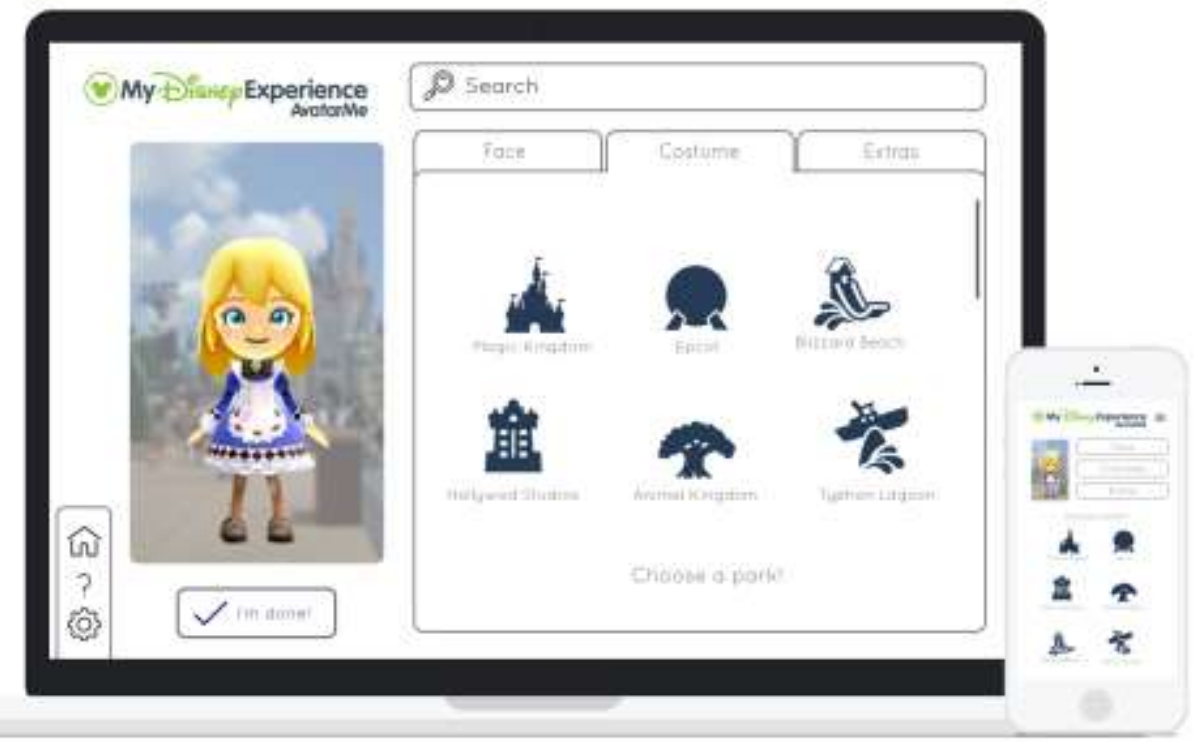

Figure 24: Web Application - Choose a park ${ }^{15}$

Figure 24 illustrates how AvatarMe looks when a guest wants to change their costume. The first step is to choose the park that the costume comes from.

\footnotetext{
${ }^{15}$ Search, Home, Settings icons: (Freepik, 2017) Costumes illustrated: (h.a.n.d., \& Bandai Namco Games) Image of Magic Kingdom in the background: (So, 2017) Disney Park icons: (Disney, 2017, My Disney Experience)
} 


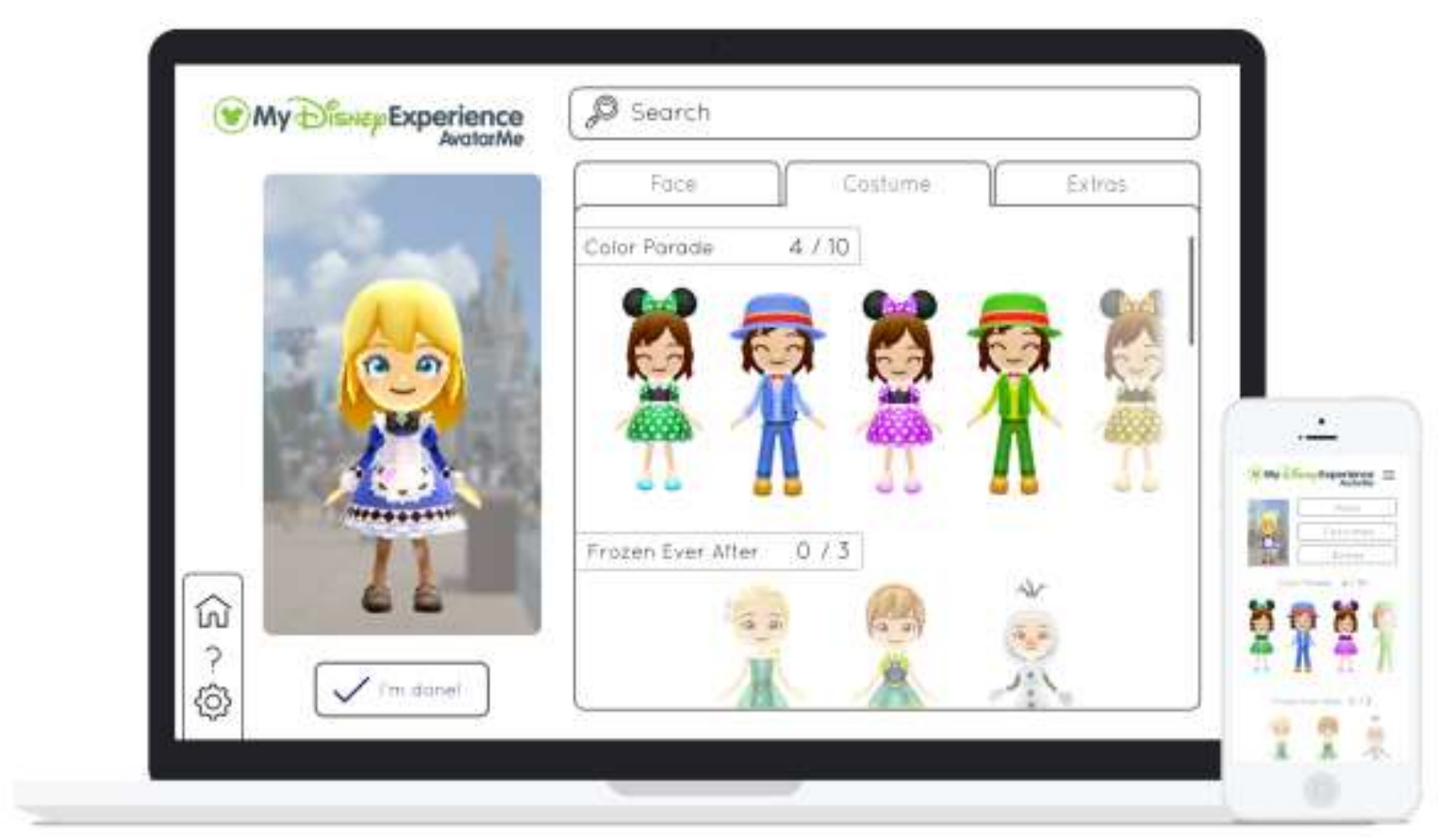

Figure 25: Web Application - Choose a costume

On the next screen, the tabs show the main customization options: face, costume, and extras (Figure 25). The right panel shows the different costumes that the guest can collect, as well as costumes they have not yet earned. Guests can see that if they were to queue in line for the Frozen Ever After Ride at Epcot, they could play games in order to earn the Elsa, Anna, and Olaf costumes for their avatars. This is to create incentive for the user to visit the other rides and parks throughout Walt Disney World. Additionally, guests can use the search function in order to find a specific costume that they are interested in.

The purpose of being able to see the various costumes is vital to the success of an avatar system. Games with goals stimulate the player's senses and give them compelling interaction (Lazzaro, 2004). As mentioned earlier in the paper, goals also engage and immerse the player more. By structuring the experience in the pursuit of a goal (collecting all of the different outfits), players will actively aim to ride all of the different attractions, make return visits for the limited edition costumes, and participate in this avatar community. In addition, by having a set goal, this is reminiscent of Maister's tenets of having a known wait is better than an unknown wait. By giving players a visualization of how many costumes they have left to collect, they will be more willing to actually complete the game. AvatarMe would be in line with collectibles community in theme parks. 


\subsection{Enter}

The enter stage happens when the guest physically enters the park and is able to interact with the system and other users in the park. This stage contains the wristband device that the users are wearing throughout the park to interact with the games and the contact points where users can enter the system at each game. This is also in line with Kirschner and Williams' conclusions about needing purpose to create engagement in digital games (2014).

\subsubsection{Wristband Device}

In order to use the system, guests will be able to borrow a wristband from the park upon entering the park. Figure 26 illustrates what a mock-up of a wristband with two buttons could look like.

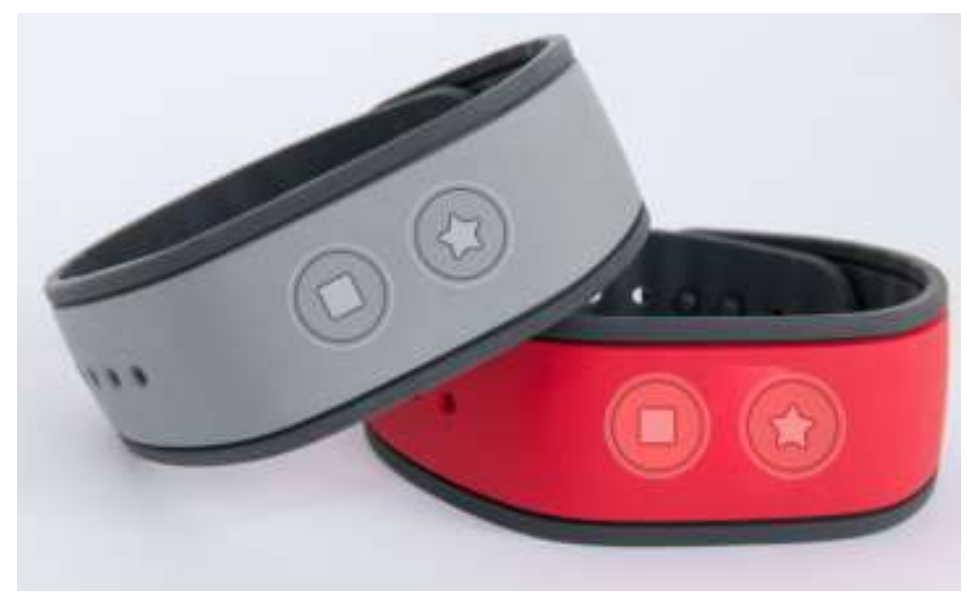

Figure 26: Wristband Device

The wristband contains an RFID, an accelerometer, and 2 buttons for interactions. The RFID allows the system to recognize when a wristband is being used for a ride (and which specific ride contact point), as well as linking the activity back to a user. The RFID chip will also be used to determine the location of the bands at all times to ensure that guests return the band at the end of their visit.

The accelerometer allows the wristband to determine the speed at which the arm is moving and in what direction. The two buttons are for basic functions such as answering trivia questions. The purpose of choosing shapes as the button faces instead of numbers or letters allows the wristbands to be used with children of a younger age. 
In addition, this makes the system more user-friendly as shapes are easier to read and recognize as opposed to letters or numbers. These four pieces of hardware allow for a variety of different games and applications to be used with the wristband. The device would need to be water resistant, as well as have a strong locking mechanism, which would allow the device to stay on during more thrilling rides.

\subsubsection{Contact Point}

Similar to the contact points for the Disney MagicBand, this is an RFID tower which allows guests to press their MagicBands against it in order to indicate that they are using that particular checkpoint. In Walt Disney World, these contact points are used in various places - at the entrance as a ticket, throughout the park in the retail stores for payment, as well as for guest identification. In my avatar theme park system, there will be a contact point located near or underneath each of the screen installations to allow guests to interact with the screen and game. Figures 27 show the various types of Disney MagicBand contact points.

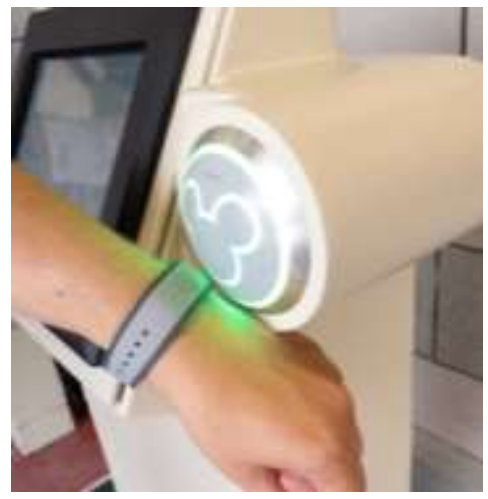

Figures 27a: MagicBand Contact Point Example $1^{16}$

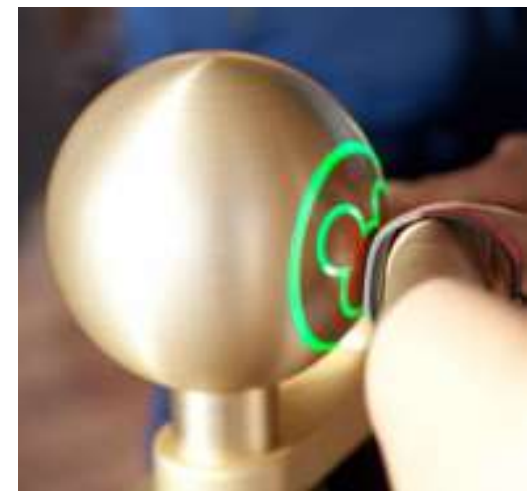

Figures 27b: MagicBand Contact Point Example $2^{17}$

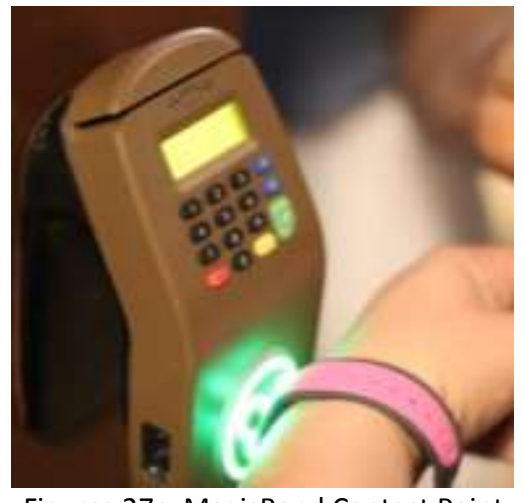

Figures 27c: MagicBand Contact Point Example $3^{18}$

Figures 27: Contact Point

\subsection{Engage}

The engage stage is the stage where the application attempts to engage guests in using AvatarMe by ensuring that the system is both inviting and simple to use. The guest can be motivated to use the system through its accessibility, collecting rewards, and the social aspect. By engaging the guest, they build a sense of commitment to the character

\footnotetext{
${ }^{16}$ (Young, 2016)

${ }^{17}$ (Alan, 2014)

18 (Lane, 2015)
} 
that they are playing, to the community, as well as to the game as a whole (Boudreau, 2007).

\subsubsection{Queue Line Entertainment}

Games designed for the wristband system must be simple to learn and quick to play. As explored previously, decisions made by users are determined by the degree to which they feel compelled by what they experience, and therefore, how immersed they feel in the virtual world (Usoh et al., 1996). This means that the more immersed the player feels in a game, the more they will desire to interact with the virtual world. Games and interactions through an avatar system must blend seamlessly into the theme park, and not break the guest's immersion at the park. At the same time, there is not forgetting of the guest's actual reality. Instead, guests fall into what Coleridge calls a 'willing suspension of disbelief (1906). The queue games must give guests control, a challenge, while also immersing them fulling in order to fully engage guests (Kirschner \& Williams, 2014).

Since the queue line length can be unpredictable, it also is recommended that there are several different random short games that cycle in one given place, so that for periods of high traffic, guests will not become bored of watching and playing the same game over and over again.

Additionally, when a guest identifies with their avatar, they experience the same feelings that result from the interaction of the goals and events that take place digitally. Oatley believes that because of this, happiness should result from events that promote the character's goals, and anxiety results from those that threaten the success of the goals (1994). From this, games that are designed need to promote the collection aspect and promote a sense of joy and happiness for moving forward in their goals.

\subsubsection{Screen Installation}

The second portion of the design involves the main screens that are situated throughout the park. These screens show the games that guests can participate in playing. Figures $27 \mathrm{a}$ and $27 \mathrm{~b}$ illustrates where a screen and contact point (see previous section for Contact Points) could be installed in the queues of Harry Potter and the Forbidden Journey at Universal. In Figure $27 \mathrm{a}$, the screen is in the middle of the queue guests enter from the right side of the image, are able to scan their device, and then 
move to the left side of the screen to follow the queue. This means that the guest can be playing the game for the entire left side of the queue.

Screens are installed high above guest eye lines in order to create a point of interest for all guests, and not just the guests playing. In addition, the screens are installed towards the back of each room so that there is anticipation building for the queue. The guests can then enjoy watching other guests play games as they move towards the screen, scan their wristband on a contact point, and then play the game until they are into the next area.

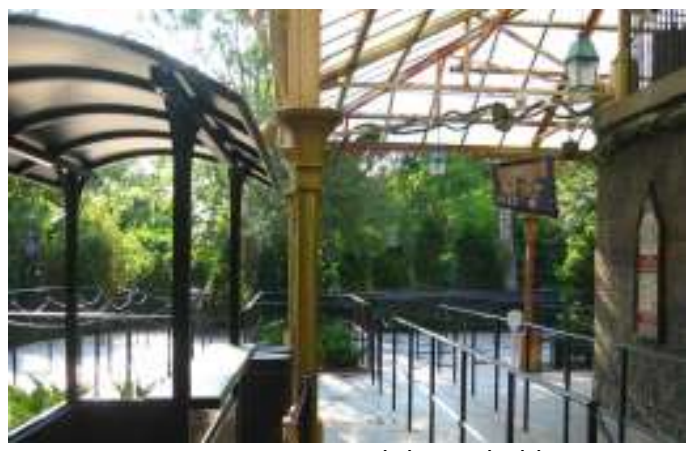

Figures 28a: Harry Potter and the Forbidden Journey Screen Installation ${ }^{19}$

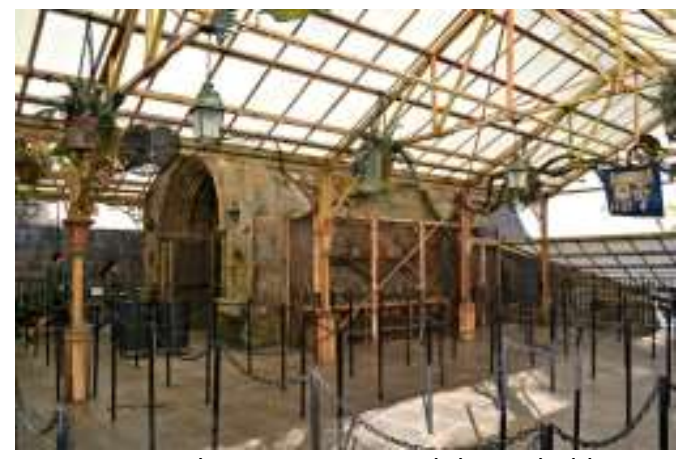

Figures 28b: Harry Potter and the Forbidden Journey Screen Installation ${ }^{20}$

Figures 28: Screen Installations

During gameplay, guests will be able to see their personalized avatars on the screens as they are playing games. This places the guests directly into the game, as they have created a bond with their avatar. The more time spent interacting and playing with the avatar, the stronger their emotional bond with their avatar will be (Turkay, 2013).

\subsubsection{Payment Services}

Current wristband devices like the Disney MagicBand have payment services built into the wristband. In retail stores, guests have the ability to tap their MagicBand linked to an account against a contact point in order to pay for their merchandise. At Universal's Volcano Bay, guests can also link their TapuTapu wristband to a credit card, allowing them to leave their belongings in a locker all day, and instead, use the wristband for payment services throughout the waterpark. In Hong Kong, the Octopus card is integrated throughout the entire commerce ecosystem. People are able to use their oyster cards for the transit system, at many retail stores throughout the entire city, on-street parking meters, or even for vending machines. In fact, they have also created

\footnotetext{
${ }^{19}$ (Brigante, 2010)

${ }^{20}$ (Marcelle, n.d.)
} 
wristwatches that embed the Octopus chips, allowing people to simply wear a regular watch throughout the day, making the usability and accessibility of the Octopus card even simpler. Payment services must be integrated throughout the park to ensure accessibility and convenience for guests.

\subsubsection{Merchandising Opportunity}

Merchandising options is another important consideration of the engage stage. Since these digital avatars exist only in the digital realm, there is an opportunity to make them into real figurines that guests can purchase and bring home. This would encourage guests to find their favourite costumes and outfits throughout the park. If guests were to visit the different parks multiple times, or stay in a park resort, this could be implemented into the existing park infrastructure - for example, after a day at the park, guests could receive an email or notification back in their hotel room about the option to purchase a figurine of themselves dressed up in the avatar costume. They could purchase it inside the park system, and then it could be in their hotel room the next day. This encourages guests to reflect and think back on their avatar experience throughout the park, as well as afterwards - the extend stage of the user experience.

In Animal Kingdom, Disney has proven the viability of a print-on-demand service that replicates the facial features of a guest with their Avatar action figure (Figure 29). The action figures are made on the spot, and guests are able to take it home immediately after purchase.

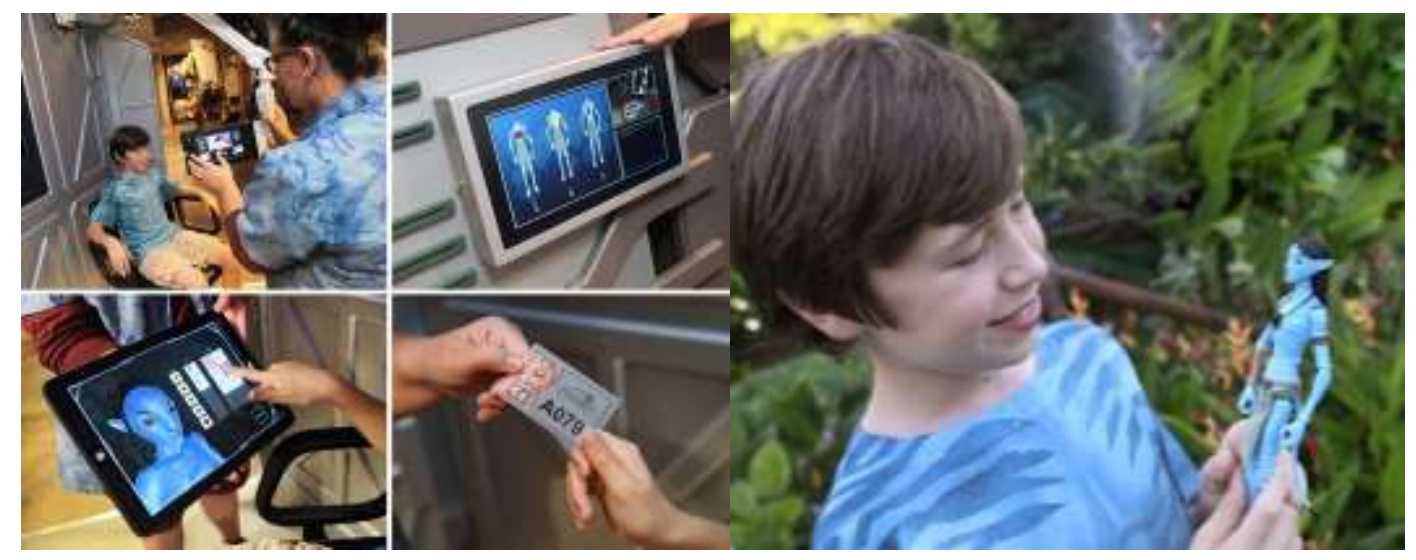

Figure 29: Avatar Action Figure at Disney Animal Kingdom ${ }^{21}$

\footnotetext{
${ }^{21}$ (Miller, 2017)
} 


\subsection{Exit}

The exit stage is one of the final stages - it is how the experience appears to end for most users. This occurs when the guest has finished with the day (or trip) at the park, and has finished their last interaction with the avatar system.

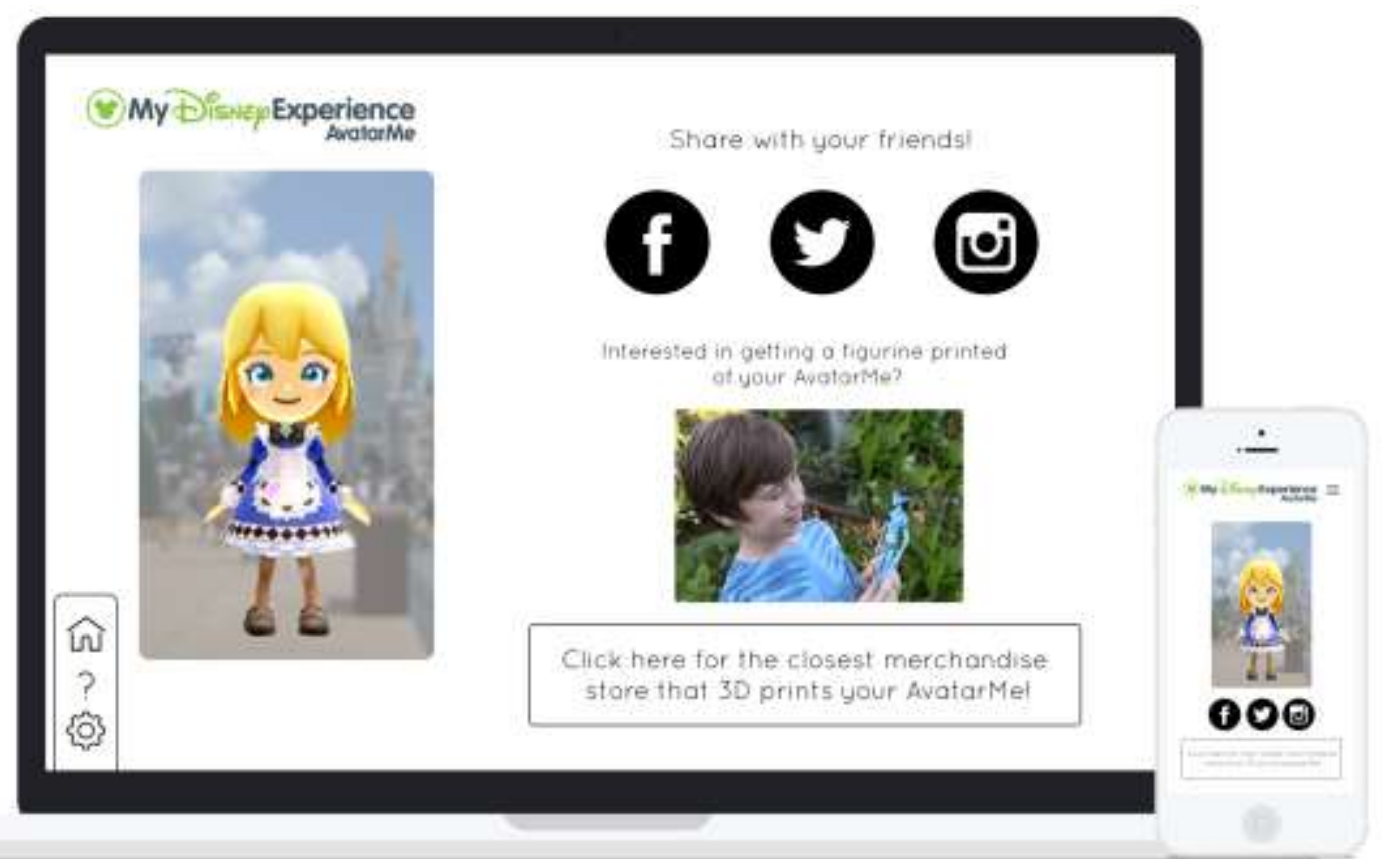

Figure 30: Web Application - Share your AvatarMe $\mathrm{Me}^{22}$

Prompting the guest to share their avatar through social media will help grow the platform, and create a community (Figure 30). Sharing content with people out of the trip can actually trigger reflection and a new interpretation of the current experience (Moores, 2003). As part of the exit stage of each application interaction or screen interaction is reminding guests how they can change their avatars outfits as soon as they earn a new outfit, and making it easy for them to share. The ability to connect and share photos has been proven to be integral to a positive experience (Durrant, Golembewki, Kirk, Benford, Rowland, \& McAuley, 2011).

An important consideration of the exit stage includes how smoothly the return process occurs for guests. Since the exit stage is the last experience that the guest has with cast members and the application directly, it is important to have a good final impression.

\footnotetext{
${ }^{22}$ Photograph (Miller, 2017)
} 


\subsection{Extend}

The extend stage is the stage that happens after the guest has left the park. The extend stage is just as important as the beginning engagement stages because players still feel connected to their avatars far after they have stopped playing the game (Boudreau, 2007). Customization increases the value of the character for the player. In Turkay's study, she observed that users had an increased attachment over sessions the more that the player interacted with the avatar; the more likely they were to come back and interact with the avatar again (2013). In order to extend the experience, very simple steps can be taken - even now, Disney and Universal both send out emails after trips to encourage guests to return at a later date, often with coupons or deals for return guests. This could instead be customized with the guest's avatar, so that guests can visually picture themselves at the park again.

Another reason for the importance of the extend stage is that the theme park industry as a whole has entered a mature stage and is no longer experiencing high growth in terms of new development (Heo \& Lee, 2009). Instead, theme parks have become highly dependent on return visitors. By extending the experience, guests are more likely to return. 


\section{DISCUSSION}

The queue in the theme park has a unique role where it may act multifunctional. It firstly, acts as a way to hold the guests physically in order to ensure a fair and orderly line to the attraction. It also acts as an on-boarding show for the attraction for guests both for guests who may have experienced the IP or the attraction before, as well as new guests. Finally, it also acts as entertainment in order to ensure that guests are engaged and enjoying their time in the park. The current methods include using interactive queues and changing the style of queues (open-space or virtual queues).

It is clear both in the academic research and the data collected that there is a unique emotional bond between a user and their avatar - in fact, most people see the avatar as an extension of themselves in a digital world. When a user creates an avatar, they are not only joining a community, but creating a new community as well. As mentioned previously, when a user identifies with their avatar, it is more likely to increase enjoyment, involvement, and evoke intense emotional responses (Cohen, 2001). By harnessing this emotional bond between the user and their avatar, and utilizing the queue, a more engaging experience can be created for the guest. The emotional bond and identification with their avatar means that the guest will feel the same connection to the ride, and the park itself.

\subsection{Mobile Devices}

Mobile phones are a huge part of guest behavior in theme parks. In fact, according to Toni Caracciolo, vice president of marketing for SeaWorld Parks \& Resorts, people are using their mobile phones to "enhance their experience [...], it's actually engaging throughout the entire day" (Bevil, 2014). Theme parks have also begun to embrace this idea, with many parks implementing free park-wide wifi, as well as mobile applications. In addition to actually providing free wifi for guests, Disney has even began to camouflage outlets within rest areas of Magic Kingdom. Seaworld's waterpark, Aquatica, has also started testing locker-style systems that allow guests to charge their devices (Snow, 2014). According to data collected on-site, 29\% of guests were actively looking at photos or taking new photos. Disney had not integrated any special Snapchat geolocation filters for guests who were using Snapchat, while Universal Studios had. This is a very simple implementation that was missing, especially considering how 
many guests were taking photos. Disney may also simply choose not to incorporate Snapchat filters because they have no need to. This is in line with Wang, Xiang, and Fesenmaier's research where they wrote that tourists are more likely to share and document experience while they are en-route or on-site because of the convenience of the smartphone, and the instant feedback and reward from social activities (2014). Even without the feedback and reward-giving behavior from other social media users, some users still acquire a sense of satisfaction and happiness simply from just sharing their experiences with others (Wang et al., 2004). Additionally, while users used to upload photos to social networks after the trip, with the growth of smartphones, they are able to upload them on the spot (Wang et al., 2004). This shows a shift in the behavioral use of mobile devices.

Depending on the hours of the day, it was observed during the on-site study that guests were more likely to be planning their day through the My Disney Experience application at the beginning of the day, and looking at their photos towards the end of the day. Additionally, guests were more likely to be looking at the My Disney Experience application in Animal Kingdom than at Magic Kingdom. In Magic Kingdom, guests were instead much more likely to use the paper map. Animal Kingdom features Pandora, the World of Avatar, and the newest opened area of any of the Disney parks. This part of the park features several features that are directly linked with the My Disney Experience application including GPS location notifications about ordering food at the restaurant nearby for later pickup. Since guests would already have their mobile devices out due to the different notifications, they would be more likely to continue to use their mobile devices. Magic Kingdom, on the other hand, is an older park in comparison.

When comparing the data collected from the survey and the on-site observational study, it appears that people self-reported themselves using their phone more than when actually observed in Florida, $69 \%$ in the survey to $37 \%$ on site. Part of this is due to the fact that respondents may have distorted memories of what they actually do in lines. Secondly, the respondents in line are different from the guests at a theme park. At a theme park, the queue is designed with entertaining the guest in mind, while in lines at Starbucks and food counters are not necessarily designed or themed purposefully. 


\subsection{Avatars}

It is clear from the data that Bitmoji users view their Bitmoji as a direct representation of themselves, and that they want their avatar to look and dress the way they do normally. This is in alignment with academic studies which state that players will tend to dress and act like the way they do outside of the digital world (Waggoner, 2009; Usoh, Alberto, \& Slater, 1996; \& Ryan, 1999). There is an emotional connection created between the user and the avatar when they have the ability to make the avatar look like and do whatever they would like them to. In the online survey, all of the respondents responded to questions 14 and 15 the same - "Describe the way you look", and "Describe the way your Bitmoji looks". In addition, six of the respondents included their height in their description of themselves - this shows that height and build is a key feature of a person's appearance, although not included in Bitmoji's options. The physical similarities between them and their avatar created a stronger emotional bond, causing them to feel more engaged and more motivated to use the avatar. This is something that needs to be kept in consideration for any future avatar platforms.

According to the data, the main reason that people made Bitmoji avatars was for "fun", or to "express themselves". This sense of fun and expression is a key part of creating an avatar and the use of the avatar. Without the fun factor, and without being able to share with others, the user has a lack of motivation to create said avatar. They were more likely to use Bitmoji if their friends were also on the platform. This shows how creating an avatar can create a community in of itself, outside of their real-life communities. This is linked to how they need the ability to express and share their avatar with others because they are part of a community that does that.

\subsection{The Queue}

On a day-to-day basis, people reported that they tend to use their phones in lines for browsing social media and messaging friends the most. This data changed once inside theme parks, with the most phone users using them for browsing and taking photos, with messaging people as the secondary form of usage in queues. This shows that there is a shift in guest activity when they enter a theme park. Instead of focusing purely on the social media aspect, guests are focusing more on documenting the experience, followed by sharing that experience with others. 
In terms of playing games, only $3 \%$ respondents originally stated that they would play games on their phones, but while in queues, $24 \%$ listed games as the activity they do most often in queues (only following talking to friends at 43\%). This shows that when the user is standing in line looking to pass, a large percent of people will take out their phone to play games they would not normally play. This was also observed in the on-site study where guests who walked past the interactive digital games in the Winnie the Pooh queue and the Seven Dwarfs Mine Train queue, would swipe on the screens at least once to see the interaction.

Most major theme parks have implemented several aspects of Maister's tenets of an ideal queue, the first, "occupied time feels shorter than unoccupied time" (2005). This is evident by the interactive games, props, and scenery pieces that are seen throughout the queues. The second, "people want to get started", is particularly evident in Universal queues where portions of the story are told to the guest as they move through the queue, with a room or door separating each portion of the story (Maister, 2005). By splitting up the story into several waiting areas and rooms, also known as the phases, the guest can feel like part of the attraction has started because of the story being told (Cope et al., 2010). The fourth, "uncertain waits are longer than known, finite waits" is seen by the wait time signs posted at the front of each attraction, as well as on the various applications (Maister, 2005). The fifth, "unexplained waits seem longer than explained waits" can be noticed whenever an attraction breaks down, there is a script that the cast members follow to let guests know what has gone wrong, and sometimes, how long it will take to repair (Maister, 2005). The eighth, "solo waits feel longer than group waits" is built into the design of the queues (Maister, 2005). The purpose of the switch back queue is to encourage comradery and sociality.

According to the data, the main purpose that people purchased passes that allowed them to skip the line was because they hated waiting in line, and secondly, because they wanted to ride as many rides as possible, and they had a limited amount of time in the park. This shows how the guests are trying to get the best out of their limited time at the park because of the amount of money they have spent. This shows that they are cognizant of the money they have spent entering the park throughout the park and will spent more money to ensure that they are not, as they feel, wasting time in the queue. 


\subsection{Limitations of Research}

There are more theme parks in the United States in comparison to Canada. In an attempt to alleviate responses from just Canada, the survey was advertised on more American-focused websites like Reddit and Twitter. The survey was created and conducted prior to the on-site observational study, although it would have been more beneficial to switch the order in which these were conducted in order to design a more informed questionnaire.

The largest age group of the respondents were 21-24 year olds (42\%), which could also potentially skew the results due to their high phone usage and their growth with the internet as a whole. According to IAAPA's 2013 Family Entertainment Centers State of the Industry survey, the demographic for theme parks are families with children from the ages of 2-18. This means that the on-site observational study guests do not necessarily follow the same behaviours as the respondents from the survey.

One of the limitations of the observational research were that the guests observed were only a fraction of the total guests who attended the parks on said days. The guests observed were also limited by my personal position in the line, and the particular guests in line at the same time. Additionally, Volcano Bay was only open for a month prior to the on-site visit, and so it was expected that there would be kinks and problems that the park had not yet worked out. In particular, improvements to the TapuTapu coding will still be rolled out as the park tests their system with more guests.

\subsection{Barriers and Limitations}

Current limitations of AvatarMe may include how a guest exits a game area once they have moved on in the queue but before they join the new game. This could easily be rectified by having the guest play a set number of games for each screen, and once those games are over, the avatar just interacts with the guest - for example, if a guest jumps up and down, moving the accelerometer embedded in the wristband, then the avatar on screen will do the same. Alternatively, another option would be to have the game end once an RFID chip is a certain distance away from the contact point. This may cause problems if a guest taps the contact point, and then moves along in the queue quickly. Regardless, this will be a major limitation that will need to be explored more in depth in future research and study. 
The upkeep and cleanliness of the wristband is another important consideration. In Epcot, after each 3D show, the glasses are picked up and then cleaned at a wash station at 160 degrees (Henley, 2013). Of course, this would destroy the internal components of the wristband. This will be something to look into as Universal Studios rolls out the TapuTapu system at Volcano Bay, which utilizes borrowing a wristband device when you visit the park.

The financial cost is a large barrier to adoption of AvatarMe. Disney invested $\$ 1$ billion dollars into implementing the MagicBand in order to create a frictionless system that integrates with every aspect of the park (Kuang, 2015). AvatarMe would cost more (unless integrated into a wristband system that already exists), as screen installations and application development would also need to be financed.

Another limitation to be kept in mind is whether the original IP holders will allow such installations in their queue lines. For example, in Universal Studio's Wizarding World of Harry Potter, the author, J.K. Rowling, has very strict creative control over what happens in the park, so installing screens may not be up to her rules for the land. This will depend from ride to ride, so it is possible that an avatar system would be implemented differently depending on the IP - for example, perhaps for the Harry Potter ride, a guest would simply have to just tap their wristband on a statue which would give them the Harry Potter themed costume for their avatar. This allows for the guest to still collect a themed costume, while not breaking the illusion of the wizarding world by installing a screen.

Since this system is supposed to represent guest personas, it is also important to keep accessibility needs in mind while designing this system. Things like having the option for wheelchair-friendly or amputee-friendly avatars should be an important consideration in order to ensure that guests of all kinds feel welcome in the park. Universal design also applies in this case - the application, interactions, and games should take in account different cognitive, visual, and audio levels of guests. Accessibility is already an important consideration in theme parks as they need to ensure a safe, fair, and enjoyable experience for all people.

As more technologies are discovered and improved, it is important to keep an eye on them for future investigation. Special attention should be paid to Universal's Volcano Bay, especially as they begin to refine and make changes to the system, both in physical maintenance and technological changes. 


\subsection{CONCLUSION}

When this research first began, three research questions were determined in order to focus in on the design and the research. The first was "how can you increase user engagement through the use of avatars in queue lines in a theme park?" By integrating games and creating the motivation for guests in queue lines through the avatar, guests will be more engaged and interacting more with the park. The key factor is the motivation behind creating the avatar - the collection culture is huge in the theme park industry, and is an important aspect to keep in mind. The second research question, "through this avatar system, how can a better user experience and an emotional bond to the park be created, in order to create a more engaging and valuable experience in the queue?" As seen in the research, customization and personalization of the avatar creates a stronger emotional bond between the user and their avatar. By using this bond and collectibles features, theme parks can create a much more engaging experience for guests. The final question, "How can an avatar system be designed with the end-user in mind by creating motivation for its use?" The guests are at the core of everything theme park related and even more so for an avatar system that is meant to be the digital representation of the guests themselves. AvatarMe does attempts to address each of these questions, but will require development and testing in order to truly evaluate its effectiveness.

The queue has never just been a place to line up and wait. It is always been a place of story and on-boarding, but unfortunately, a place where, in the guests' minds, they waste their time. By improving the experience and the story in the queue, theme parks can hope to make the queue an important part of the theme park experience instead of one that guests try to avoid. AvatarMe is a system that uses the emotional bond between a guest and their digital avatar to create a more personalized and engaging experience throughout the park, and in particular, the queue. By gamifying the queue, and creating the motivation for guests to interact with AvatarMe, guests will have a more beneficial and engaging experience in the queue, leading to a stronger emotional connection to the attraction, and to the park itself. 


\section{APPENDIX A}

The following is the online survey questionnaire, conducted through SurveyMonkey and approved by Ryerson Research Ethics Board.

\section{PART ONE: GENERAL}

\begin{tabular}{|c|c|}
\hline Gender: & $\begin{array}{ll}\text { - } & \text { Male } \\
\text { - } & \text { Female } \\
\text { - } & \text { Other } \\
\text { - } & \text { Prefer not to disclose }\end{array}$ \\
\hline Age: & $\begin{array}{ll}\text { - } & 18 \\
\text { - } & 18-20 \\
\text { - } & 21-24 \\
\text { - } & 25-27 \\
\text { - } & 28-30 \\
\text { - } & 31-40 \\
\text { - } & 41-50 \\
\text { - } & 51+\end{array}$ \\
\hline $\begin{array}{l}\text { What do you normally use your } \\
\text { smartphone for? }\end{array}$ & $\begin{array}{ll}\text { - } & \text { Read articles/websites on my phone } \\
\text { - } & \text { Browse social media } \\
\text { - } & \text { Play phone games } \\
\text { - } & \text { SMS/Messaging friends } \\
\text { - } & \text { Phoning friends } \\
\text { - } & \text { Take photos } \\
\text { - } & \text { Other: }\end{array}$ \\
\hline $\begin{array}{l}\text { When you wait in lines, what do you } \\
\text { normally do? Rank them from 1-10, } 1 \\
\text { being most often, while } 10 \text { meaning least } \\
\text { often. }\end{array}$ & $\begin{array}{l}\text { - } \text { Read articles/websites on my phone } \\
\text { - } \text { Browse social media } \\
\text { - } \text { Play phone games } \\
\text { - } \text { Talk to friends (face to face in line) } \\
\text { - } \quad \text { Talk to friends (through phone/social media) } \\
\text { - Take photos } \\
\text { - Day dream/stand quietly/think quietly } \\
\text { - Other: }\end{array}$ \\
\hline
\end{tabular}

\section{PART TWO: BITMOII AND SNAPCHAT}

\begin{tabular}{|c|c|}
\hline Do you use Snapchat? & $\begin{array}{l}\text { - } \quad \text { Yes } \\
\text { - } \\
\text { No }\end{array}$ \\
\hline How long have you used Snapchat for? & $\begin{array}{ll}\text { - } & <6 \text { months } \\
\text { - } & 6-12 \text { months } \\
\text { - } & 12-18 \text { months } \\
\text { - } & 2+\text { years }\end{array}$ \\
\hline Do you use Bitmoji? & $\begin{array}{l}\text { - } \quad \text { Yes } \\
\text { - } \\
\text { No }\end{array}$ \\
\hline $\begin{array}{l}\text { If yes: How long have you used Bitmoji } \\
\text { for? }\end{array}$ & $\begin{array}{l}\text { - } \quad<6 \text { months } \\
\text { - } \quad 6-12 \text { months } \\
\text { - } \quad 12-18 \text { months }\end{array}$ \\
\hline
\end{tabular}




\begin{tabular}{|c|c|}
\hline & - $2+$ years \\
\hline $\begin{array}{l}\text { If yes: How did you decide how your face } \\
\text { would look like? }\end{array}$ & $\begin{array}{l}\text { - Ideal facial features } \\
\text { - } \quad \text { Replicate my own facial features } \\
\text { - } \quad \text { Random or for fun }\end{array}$ \\
\hline $\begin{array}{l}\text { If yes: How did you decide what to wear? } \\
\text { Select all that apply. }\end{array}$ & $\begin{array}{l}\text { - Look through all clothing options } \\
\text { - Think about personal style and look for something } \\
\text { similar } \\
\text { - Random/for fun }\end{array}$ \\
\hline $\begin{array}{l}\text { Do you think you look like your Bitmoji? } \\
1-10,10 \text { meaning yes, } 1 \text { meaning no }\end{array}$ & $1-10$ scale \\
\hline Why do you use Bitmoji? & Paragraph answer \\
\hline Do any of your friends use Bitmoji? & $\begin{array}{l}\text { - } \quad \text { Yes } \\
\text { - } \quad \text { No }\end{array}$ \\
\hline What does your Bitmoji look like? & Paragraph answer \\
\hline Do any of your friends use Bitmoji? & $\begin{array}{ll}\text { - } & \text { Yes } \\
\text { - } & \text { No }\end{array}$ \\
\hline \multicolumn{2}{|l|}{ PART THREE: THEME PARKS } \\
\hline $\begin{array}{l}\text { Have you been to a theme or amusement } \\
\text { park in the last } 5 \text { years? }\end{array}$ & $\begin{array}{ll}\text { - } & \text { Yes } \\
\text { - } & \text { No }\end{array}$ \\
\hline $\begin{array}{l}\text { If yes, did you purchase any of the } \\
\text { following? }\end{array}$ & $\begin{array}{l}\text { - FastPass } \\
\text { - Fast lane } \\
\text { - Any other options that allow you to skip, bypass, or move } \\
\text { in a faster line }\end{array}$ \\
\hline Have you used a Disney MagicBand? & $\begin{array}{l}\text { - Yes } \\
\text { - No }\end{array}$ \\
\hline $\begin{array}{l}\text { If yes, do you have an annual membership } \\
\text { with Disney? }\end{array}$ & $\begin{array}{ll}\text { - } & \text { Yes } \\
\text { - } & \text { No }\end{array}$ \\
\hline $\begin{array}{l}\text { How many times have you been to a } \\
\text { Disney theme park in the past? }\end{array}$ & $\begin{array}{l}\text { - } 1-3 \text { times } \\
\text { - } \quad 4-5 \text { times } \\
\text { - } \quad 6-10 \text { times } \\
\text { - } 10+\text { times }\end{array}$ \\
\hline $\begin{array}{l}\text { When have you used your MagicBand } \\
\text { to...? Check all that apply }\end{array}$ & $\begin{array}{l}\text { - } \quad \text { Enter park } \\
\text { - Purchase food } \\
\text { - } \quad \text { Purchase merchandise } \\
\text { - Use the PhotoPass capability } \\
\text { - Other: }\end{array}$ \\
\hline
\end{tabular}




\section{REFERENCES}

Accesso. (n.d.). accesso Prism. Retrieved from http://accesso.com/solutions/loqueue/prism.

Acorn Marketing \& Research Consultants (International). (2016, November). Retrieved from http://www.octopus.com.hk/octopus-for-businesses/benefits-for-yourbusiness/en/index.html

Alan, D. (2014, March 19). Disney MagicBand, [Photograph]. Retrieved from http://www.inthemousehouse.com/my-magic-plus-101-everything-you-need-toknow-about-disneys-newest-invention/

Barnes, B. (2010, December 28). Disney Technology Tackles A Theme Park Headache: Lines. New York Times, p. B1.

Bevil, D. (2014, 27 July). Theme parks offering smart-phone options to improve visitor experience. Orlando Sentinel.

Bitstrips. (2017). Bitmoji (10.15) [Mobile application software] Retrieved from http://itunes.apple.com/

Blesgraaf, P. (2014). Redesigning the theme park queue. Journal of Motivation, Emotion, and Personality, 2(2), 74-77.

Brigante, R. (2010, May 28) Hogwarts Greenhouse, [Photograph]. InsidetheMagic, Harry Potter and the Forbidden Journey. Retrieved from: https://www.flickr.com/photos/insidethemagic/4649892791/in/album$72157624036320625 /$.

Boudreau, Kelly, (2007). Pixels, Parts \& Pieces: Constructing Digital Identity. [Master thesis]. Concordia University.

Bogdan Rosu. (2017). Flat Icon. Retrieved from https://www.flaticon.com/authors/bogdan-rosu

Bauman, Z. (2004). Identity: Conversations with Benedetto Vecchi. Cambridge, MA: Polity Press.

Cober, Steven. "Photographs at Disney Magic Kingdom." 2017. JPEG file.

Cohen, J. (2001). Defining Identification: A Theoretical Look at the Identification of Audiences with Media Character. Mass Communication \& Society, 4(3), 245-264.

Coleridge, Samuel T. (1906). Biographia literaria. London: J.M. Dent. 
Cope, R., Cope, R. F., \& Davis, H. E. (2011). Disney's Virtual Queues: A Strategic

Opportunity To Co-Brand Services? Journal of Business \& Economics Research.

Daniels, E. C. (2016). The Perception of Time Waiting in Theme Park Queue Lines (Master's thesis). Michigan State University.

Danesi, M. (2017). The semiotics of emoji. London: Bloomsbury Academic.

Disney. (2017). Tokyo DisneySea [Map]. Retrieved from

http://www.tokyodisneyresort.jp/en/tdr/about/pdf/EN_TDS_map.pdf/

Disney Emoji Maker. (n.d.). Retrieved from http://www.disneyemojimaker.com/

Disney. (2017). My Disney Experience (Version 4.7) [Mobile application software]. Retrieved from http://itunes.apple.com/

Disney. (n.d.). Select a Character. Retrieved from

https://disneyworld.disney.go.com/en_CA/profile/personal-

information/characters /

Disney's Four Keys To A Great Guest Experience. (n.d.). Retrieved from http://disneyatwork.com/disneys-four-keys-to-a-great-guest-experience/

Disney Institute. (2001). Be Our Guest: Perfecting the Art of Customer Service. New York, New York: Disney Enterprises, Inc.

Ducheneaut, N., Wen, M.H.D., Yee, N., \& Wadley, G., (2009). Body and Mind: A Study of Avatar Personalization in Three Virtual Worlds.

Duguay, Y. (2014, June 1). Checkpoint Queuing: learning lessons from Walt Disney [Blog post]. Retrieved from http://www.hciworld.ca/en/publications-en/airportauthorities-invest-planning-design-security-checkpoints-future-2/

Durrant, A., Golembewski, M., Kirk, D. S., Benford, S., Rowland, D., \& McAuley, D. (2011). Exploring a digital economy design space in theme parks. Proceedings of the Second Conference on Creativity and Innovation in Design, 273-284.

Fagundes, D. (2016). The Social Norms of Waiting in Line. Law \& Social Inquiry, 1-29.

Freepik. (2017). Flat Icon. Retrieved from https://www.flaticon.com/authors/freepik Gee, J. P. (2000, January 1). Chapter 3: Identity as an Analytic Lens for Research in Education. Review of Research in Education, 25(1), 99-125.

Griffith, E. (2017, February 7). Everything to Know About Snap's IPO. Fortune. Retrieved from http://fortune.com/2017/02/07/everything-to-know-about-snaps-ipo/

h.a.n.d., \& Bandai Namco Games. Disney Magical World. JP: Namco, \& WW: Nintendo, 2014. Nintendo 3DS. 
Henley, N. (2013, May 2). Cleaning of the 3D Glasses at Walt Disney World [Blog post]. Meet the Magic. Retrieved from http://meetthemagic.com/cleaning-of-the-3dglasses-at-walt-disney-world-2/.

Heo, C. Y., \& Lee, S. (2009, September). Application of revenue management practices to the theme park industry. International Journal of Hospitality Management, 28(3), 446-453.

Hickman, J., \& Mayer, K. J. (2003). Service quality and human resource practices: a theme park case study. International Journal of Contemporary Hospitality Management, 15(2), 116-119.

Inagaki, K. (2010, December 2). Disney Looks to Make Japan Duffy Craze Global. The Wall Street Journal. Retrieved from https://blogs.wsj.com/japanrealtime/2010/12/02/disney-looks-to-make-japanduffy-craze-global/

Joel (2011, November 9). Line Cutters Should Be Arrested. Theme Park Geekly. Retrieved from http://www.coastercritic.com/2011/11/line-cutters-should-be-arrested-2/

Johnson, R. R. (1998). User-centered technology: A rhetorical theory for computers and other mundane artifacts. Albany, NY: State University of New York.

Jones, P., \& Peppiat, E. (1996). Managing perceptions of waiting times in service queues. International Journal of Service Industry Management, 7(5), 47-61.

Kawash, S., Schwartz, J., \& Blum, S. C. (2014, August 28). United States Patent No. US 2014/0240102 A1.

Katz, K. L., Larson B. M., \& Larson, R. C. (1991, Winter). Prescription for the Waiting-inLine Blues: Entertain, Enlighten, and Engage. Sloan Management Review, 32(2), 4453.

King, M. J. (1991, November-December). The Theme Park Experience: What Museums Can Learn from Mickey Mouse. The Futurist, 25(6), 24-31.

Kirschner, D., \& Williams, J. (2014). Measuring video game engagement through gameplay reviews. Simulation \& Gaming, 45(4-5), 593-610.

Kuang, C. (2015, March 10). Disney's \$1 Billion Dollar Bet On a Magical Wristband. Wired. Retrieved from https://www.wired.com/2015/03/disney-magicband/

Klimmt, C., Hefner, D., Vorderer, P., Roth, C., \& Blake, C. (2010). Identification With Video Game Characters as Automatic Shift of Self-Perceptions. Media Psychology, 13, 323338.

Lane, B. (2015, August 11). Disney Magic Bands provide the ultimate customer experience. One of the many reasons why the Apple Watch could drive Apple Pay adoption, [Photograph]. Retrieved from http://blog.passkit.com/will-the-apple- 
watch-drive-apple-pay-adoption/

Lazzaro, N. (2004). Why we Play Games: Four Keys to More Emotion in Player Experiences. XEODesign.

Ledbetter, J. L. (2016). Interactive Amusement Park Queues: Examining the Indirect Effect of Task Work Load on Guests Perception of Wait Duration Through Task Immersion [Doctor of Philosophy thesis]. University of Central Florida.

Lukas, S. A. (2008). Theme Park. London, UK: Reaktion Books Ltd.

Maister, D. H. (2005). The Psychology of Waiting Lines.

Marcelle, K. (n.d.). No lines in the greenhouses at Hogwarts Castle before the park opens, photograph]. Retrieved from http://ciaobambino.com/universal-orlando-resorttips /

Merritt, C., \& Lynxwiler, J. E. (2010). Knott's Preserved: From Boysenberry to Theme Park, the History of Knott's Berry Farm. Angel City Press.

Miller, S. (2017, May 30) Create Your Own Avatar Action Figure at ACE Avatar Maker in Pandora - The World of Avatar, [Photograph]. Disney Parks Blog. Retrieved from: https://disneyparks.disney.go.com/blog/2017/05/create-your-own-avataraction-figure-at-ace-avatar-maker-in-pandora-the-world-of-avatar/

Molla, R. (2017, April 7). Snapchat's Bitmoji is the No. 1 most-downloaded app in five top markets. Recode. Retrieved from https://www.recode.net/2017/4/7/15191464/snapchat-facebook-googletwitter-uber-bitmoji-app-downloads/

Moores, S. (2003). The doubling of place: Electronic media, time-space arrangements and social relationships. Mediaspace: Place, scale, and culture in a media age. Pg 2136: London, Routledge.

Nelson, E. (2016). The art of queueing up at Disneyland. Journal of Tourism History, 8(1), 47-56. doi: 0.1080/1755182X.2016.1179795

Niles, R. (2014, June 19). Can virtual queues eliminate all of a theme park's lines? [Blog post]. Retrieved from http://www.themeparkinsider.com/flume/201406/4082/

Null, R. (2013, August 28). Universal Design: Principles and Models. CRC Press.

Oatley, K. (1994). Meeting of minds: Dialogue, sympathy, and identification in fictional narrative. Poetics (23), 53-74.

Omnico Group. (2016-2017). The Chinese Theme Park Barometer 2016-2017 [Report]. 
Ondrejka, C. (2004). Escaping the gilded cage: User created content and building the metaverse. Paper presented at the Institute for Information Law and Policy Symposium: State of Play: II. New York, NY.

Orlando Informer. (n.d.). TapuTapu at Universal's Volcano Bay - Complete Guide. Retrieved from https://orlandoinformer.com/universal/taputapu-volcano-bay

Pearce, C. (2009). Identity as Place, The Inner Lives of Avatars, and Being Artemisia; My Life as an Avatar (pp. 85-124, 215-259). Communities of Play: Emergent Cultures in Multiplayer Games and Virtual Worlds. Cambridge, MA: MIT Press.

Reddit. (2012). Disney's VMK - 5 years later [Reddit post]. Retrieved from https://www.reddit.com/r/disney/comments/1es2y7/disneys_vmk_5_years_later /ca37v8r/

Rahn, S. (2000). Snow White's dark ride. Bookbird Inc., 38(1), 19-24. doi: 0006-737

Ryan, M. (1999). Immersion vs. Interactivity: Virtual Reality and Literary Theory. SubStance, 28(89), 110-137.

Shallcross, J. (2015, May 24). How Much Do Theme Park Tickets Cost in 2015? [Blog post]. Retrieved from http://tripsandgiggles.com/story/how-much-do-themepark-tickets-cost-in-2015

Snap Inc. (2017). Snapchat (Version 10.15.1.0) [Mobile application software]. Retrieved from http://itunes.apple.com/

Snow, M. (2014, June 30). SeaWorld Orlando Offers New Cell Phone Charging Stations. CitySurfing Orlando.

So, Winona. "Photographs at Disney Magic Kingdom." 2017. JPEG file.

So, Winona. “TapuTapu Onboarding Pamphlet.” 2017. JPEG file.

Statt, N. (2016, August 6). Snapchat's biggest threat is its own design. The Verge. Retrieved from http://www.theverge.com/2016/8/6/12388880/snapchatinstagram-stories-copied-design-clones/

Thinkwell Group. (2013). Thinkwell's 2013 Guest Experience Trend Report [Report].

Turkay, S. (2013). The Effects of Customization on Player Experiences in an Extended Online Social Game: A Mixed Method Study [Doctor of Education thesis]. Teachers College, Columbia University.

Universal City Studios LLC. (2014). U.S. Patent Identifier No. 2014/0240102 A1. Florida: U.S. Patent Application Publication.

Usoh, M., Alberto, C., \& Slater, M., (1996). Presence: Experiments in the Psychology of Virtual Environments. 
Waggoner, Z. (2009). Locating Identity in New Media Theory. My Avatar, My Self: Identity in Video Role-Playing Games (pp 21-47). Jefferson, NC: McFarland \& Company, Inc., Publishers.

Wang, D., Xiang, Z., \& Fesenmaier, D. R. (2014). Adapting to the mobile world: A model of smartphone use. Annals of Tourism Research, 48, 11-26. doi:

10.1016/j.annals.2014.04.008

Young, J. (2016, January 13). Disney MagicBand, [Photograph]. Retrieved from http://themeparkuniversity.com/disney/why-china-is-too-advanced-for-disneymagicbands /

Younger, D. (2016). Theme Park Design \& The Art of Themed Entertainment. Inklingwood Press. 